\title{
THE PREPARATION
}

Or

\section{ALIPHATIC AOETYLBNBS}



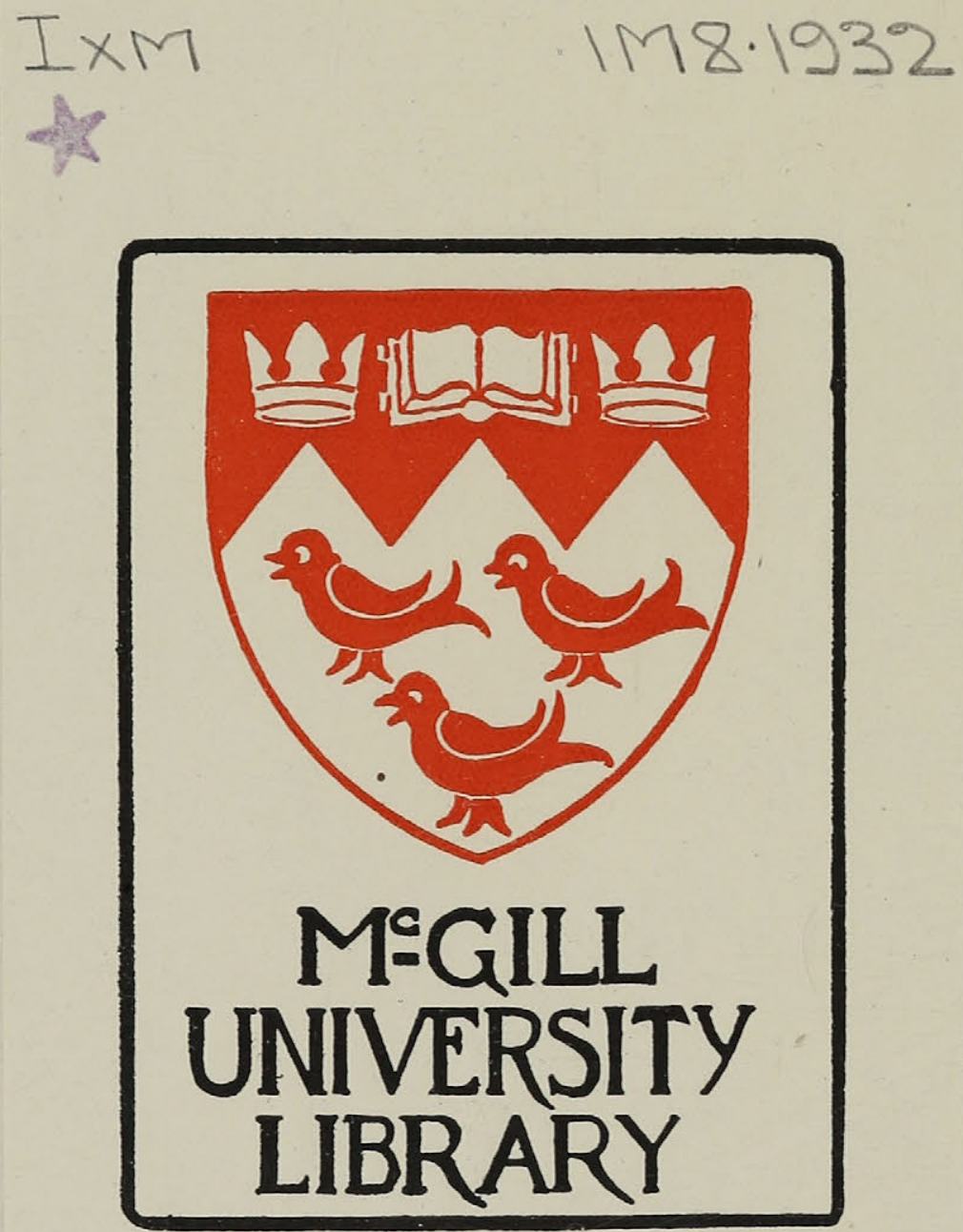

acc. No. JMA DE DATE 1932 

THE PREPARATION AND PHYSICAL PROPERTIES

On

AIIPHATIC ACETILENES

\author{
Dissertation \\ by \\ F.R.Morehouse M.Sc. \\ A Candidate for the Degree \\ Dootor of Philosophy \\ in the \\ Department of Chemistry \\ MoG111 University
}

Montreal

Apr11 1932 
The writer is grateful for this opportunity of expressing his genuine appreoiation of the help and advice so liberally given at all times by Dr. 0.Maess under whose alrection the work was undertaken. To the National Research Council of Canada acknowledgement ${ }^{-1}$ made of a Bursary and studentship during the course of this researoh. 


\section{O N T EN T S}

Page

Introductory Outline 1

General Introduction 4

Preparation of Methyl-, Ethyl-,

Propyl- and Dimethyl-acetylene 18

Parifioation of the Hydrocarbons 33

Physiosl Properties 35

(1) Density 36

(11) Surface Tension 40

(1ii) Melting Points 44

(1v) Vapor Pressures 45

Disoussion of Results 49

Summary 69

Bibllography $\quad 72$ 
Introductory Oatline.

The work to be described in this thesis deals with the preparation and investigation of the physical propertles of the lower members of an homologous series namely the alkyl acetylenes. In view of the fact that small differences in properties would be observed in the case of isomeric substances and also that the validity of the observations in the case of certain properties depends solely on the purity of the compound investigated new details have been developed in connection with the methods of preperation and special care devoted to the purification of the compounds. The propertios investigated are the physieal ones of surface tension, boiling point, density etc. This new data is of interest not only in itself but has been obtained especially with a view to the interest attached to it from a theoretical point of view in connection with the interpretation that can be made with regard to the values observed for these physical constants.

Throughout the course of several years a systematic investigation of the paraffin and olefine hydrocarbons has been undertaken in this laboratory. A comprehensive determination of their physical properties has been made and the different values obtained interpreted in terms of their probable moleculer forces of attraction. 
The continuation of this problem led to extensive experimental work whose object was to ascertain the extent and degree of the tendenoy for these compounds to undergo molecular compound formation with molecules of another type. A definite correlation was found to exist between their molecular forces of attraction and the tendency toward moleoular compound formation which wes in turn further correlated very definitely with their manifestations of intra-molecular attraction.

A continuation of this work,going on from the paraffin and olefine series to the acetylenes, is presented in this thesis. The preparation of the acetylenes by a method that will render them sufficiently free from impurities is much more difficult than is the case for the members of the paraffin and olefine serles and hence the soope of this investigation was necessarily limited by time to the first problem which is the preparation, purification and correlation of the physical properties of the aliphatic acetylenes.

In order to show the importance attached to this step In the general program of the investigation it is considered worthwhile to show the interpretation that may be put on the data obtained by referring, as an analogy, to the type and scope of a research on the parafins and olefines made possible when the preparation and measurement of the physical properties had been completed. 
A general reviow is therefore given below of the interpretation put on molecular forces of attraction and the influence they exert on the chemical and physical characteristics of compounds exhibiting such forces. 
General Introduction.

At the present time, since there is no absolute method that can give us a quantitative measurement of the relative magnitude of molecular forces of attraction, recourse must be made to investigations that will jield data of a qualitative nature and the results expressed on a relative rather than an absolute scalo.

It is well known that one of the best opportunities for the observation of relative aifferences in molecular forces of attraction betwe en like molecules lies in a comparis on of certain physical propertios, partioularly those associated with a change of state such as melting point, boiling point and critical temperature. A comparative measurement of the attract 1ve forces between unlike molecules is obtained by the extent of molecular compound formation in such systems or by the magnitude of their deviation from the laws of the ideal solution.

Thus it is that a knowledge of the physical properties of the elementary hydrocarbons is essential for an understandIng and classification of the forces of attraction that come into play between the molecules and conversely a knowledge and understanding of these forces may enable us to explain some of the abnormalities observed in various properties and may moreover lend itself to a certain amount of prediction. 
A general survey of the theories developed by investigators in this work will serve as an introduction and at the same time show further the object and interest attached to an investigation of the physical properties of the elementary hydrocarbons.

Closely associated with the adrances that have been made in defining the forces that exist between molecules and between atoms are the names of Langmuir(1) and Harkins(2) who are of the opInion that these forces are fundamentally alike in character and are of the nature of so-called chemioal forcas:

However, while modern theory tends to eliminate the distInction between physicsl and chemical forces and tends more and more to regard them as differing in degree rather than kind, it is more convenient to designate such attractive forces that may exist between unlike as well. as like molecules as"physical" in order to distinguiah it from the specific and highly selective "ohemical force" or "ohemical affinity" whose results are chemical reaction and formation of chemical oompounds.

Since a number of different opinions are held on the exact distinction between the definitions of physical and chemical force it is desirable to say a few words concerning the criteria upon which the usually accepted definitions are based. Chemical force, or what is usually knom as chemical affinity, depends definitely. on the nature and structure of the matter concerned and it's sphere of influence is limited probably to the atomic dimensions of the substance. 
On the other hand the idea of physical force is generally conceived as one which is non specific, additive and of inlimited range of action. It's influence on a given mass is independant of other masses and the direction of it's action does not depend on the nature of the mssses. Under chemical may be listed those forces which come into play when molecules such as $\mathrm{H}_{2} \mathrm{O}$ or $\mathrm{CH}_{4}$ are formed while under physicsl those manifested by such properties as melting point,latent heat and surface tension. As examples of laws governing typically physical forces may be cited Newton's inverse square law for gravitational attraction and Coulomb's law for the attraction or repulsion of electric charges.

Early attempts have been made to explain certain physicochemical phenomena by considering the force acting between molecules of liquids and gases as an attraction which varies inversely as the square of the distance between molecules but it is now well known that molecular forces of attraction vary as a high inverse power of the distance between the molecules(3). Due to the complioated nature of this problem the exact magnitude of this power cannot be determined but it is probsbly greater than four. consequently the force that gives rise to internal pressures of the order of thousands of atmospheres when the molecules are close together may become negligible when the distance between them is but slightly increased. Iangmuir has said that these forces between 
atoms and molecules involved in the structure of matter are of the same specific nature as chemical forces and since the magnitude of the forces is dependent on the specific nature of the particular atom or molecule no absolute law correlating force and distance for all molecules is possible.

However it is only in extreme cases of examples of both chemical and physical forces that a real distinction between the two is of any value or is even possible since the two forces tend to graduslly merge into one another and when an attempt is made to explain which of the forces causes the association of water molecules or that causing the formation of molecular compounds the unsatisfactory nature of such an artificial definition is at once evident.

One of the early theories concerning the mechaniem governing the combination of atoms wes the dualistic theory of Berzelius who regarded this combination as due to electric charges on each atom. According to this early theory it might happen that a molecule would form in which the respective charges on the atoms constituting it would not exactly neutralize one another. The molecule so endowed with an excess charge of either sign would then have an external field of force and possess the ability to attract other molecules and hold them if these in their turn possessed an excess of the appropiate charge.

The molecule as such has of course no residual positive or negative charge as Berzelius implied in his theory. However 
according to the modern point of view the distribution of pbsitive and negative electricity throughout the molecule is such that the centres of gravity of positive and negative electricity do not coincide. This results in an uneven distribution of the positive and negative electricity which leads to practically the seme phenomena is Berzelius suggests inasmuch as two molecules of different. species may have considerable attraction for one another in a properly orientated position due to this uneven distribution of electricity. To signify these ideas and to express them the terms "residual Affinity" and "secondary Valence" have become widely used.

Analogous conceptions of atomic and molecular attraction, although conslderably modified by subsequent discoveries, are held today and are intimately connected with our ideas of valenoy. The valency of an element may be defined as the number of hydrogen atoms or their equivalent that one of 1t's atoms is capable of holding in chemical combination. In most cases this number is well defined and always approximates an integer as in the case of carbon it is very nearly equal to four. The lence of oxygen Is almost two but that the valence of oxygen is not completely saturated with two hydrogen atoms is evidenced by the ability of water to form the unstable hydrates and oxonium compounds. This whole number-four in the case of carbon and two with oxygenhas been denoted as the primary valence while the residual force 
that remains in some cases, due to incomplete saturation, has been called the secondary valence. Thus the primary valence gives rise to the formation of molecules employing forces that are strong in comparison to the residual forces which however exist In every case and if of sufficlent magnitude give rise to more complex molecules.

Our understanding of atomic or valence forces has, of necessity been dependent to a large extent upon the knowledge at hand concerning atomic structure, a study in which amazing progress has been made in the last quarter century. Judging by the shifting sands of modern physical theory it would seem that the chemist, who had become acoustomed to visualizing atoms in terms of eleotrons, had little or nothing on which to rely. It is now considered obsolete, by physioists, to speak of static electrons in the atom. However in spite of these unaroidable difficulties and contradictions in the natural development of the science considerable progress has been made in recent years in the study of stomic structure from both the physical and chemical point of view. A sound theoretical basis for the periodic table based, not on atomic weight but atomic number, having to ko with the number and probable arrangement of the electrons in an atom, has been established, vastly-inoreasing the usefuliness of the table and developing it to a logical system.

The firm establishment of the number of electrons in any atom lent, as would be expected, a great deal to the progress and development of chemical theory. Berzelius' electro-chemical theory 
was brought to the fore in the clear cut 1dea of "electro valence" and many of the difficulties of the duslistic theory were removed by the useful conception of "covalence" either "normal" or "oo-ordinate" resulting in a reasonable explanation for much that was obscure in the physical and chemical behaviour of matter.

Modern theories of valence regard the force between atoms resulting in the formation of molecules, le."chemical", as due to the innate tendency of atoms to gain, share or lose electrons while the purely physical attraction is regarded as a secondary result of such a tendenoy. An atom or molecule can be conceived as a structure of electron orbits or vibrating electrons resulting in a stray fleld of force whose magnitudedepends on the comploteness of the screening effect of the outer electrons and the extent of internal neutralization. Two unlike molecules, having extermal flelds of force of such a nature as to more or less completely neutralize one another, may unite, or if the fields are not sufficiently large, or their mutual neutralization sufficiently complete to give rige to union, still their influence may make itself apparent in the deviation of the mixture from the laws of the 1deal solution. In the orse of molecules of the same pecies, although the forces betwe on them may not be of such magnitude as to cause association, they may greatly influence the properties of the liquid and by the comparative study of the physical properties of pure substances it is possible to obtain an insight into the relative attractive forces existing between their molecules. 
While the study of the physical properties of the hydrocarbons enables us to form some idea of the relative forces of molecular attraction between like moleoules these forces existing between unlike molecules may also be compared by the extent of molecular compound formation in such systems. In this way a study of the properties of mixtures particularly from the point of view of the Phase "Rule will throw light on the attractive forces between unlike molecules.

To recapitulate we may add another and third attractive force to the two main types of Valence recognized by modern theory. We then have (1) Electro valence, due to the electroatatic attraction between ions, (2) Covalence, due to the greater stability of certain spatial arrangements of electrons and (3) Molecular attractive force due to the resistance of stray flelds about chemical bonds or distorted atoms.

Considerable work on the subject of molecular attraction between unlike molecules has been done in this laboratory from the point of view of molecular compound formation and reaction velocities. survey of the work along these lines done by liaass and his co-workers will be given. Several types of systems have been investigated and there is distinct ovidence of such attractive forces in many cases.

Hasss and Morrison 4 have shown that when methyl other and hydrogen chloride are mixed in the vapor state there is a molecular compound formed. Compound formation in the Ilquid 
state has proved to be a very fruitful field for study. Investigations have been carried out using hydrocarbons and and the halogen hydrides as the two components. Both of these substances are ideal in that the halogen hydrides are highly polar and that by using a series of hydrocarbons great variat1ons in the external fields of force can be obtained. Mags and Russell ${ }^{5}$ have show that although toluene, ethylbenzene and mesitylene form molecular compounds with hydrogen bromide no such occurrence is noted for benzene. In an analogous manner 1t was shown that acetylene behaved similar to benzene in this respect while allylene follows the benzene homologues. It is stated that in benzene and acetylene the symmetry of the moleoule leaves apparently no secondary valence due to unsaturation by means of which an attraction is exerted on the hydrogen bromide molecules. Such an attraction would exist in the case of the alkyl substituted derivatives.

The subject of molecular compound formation along these lines was investigated more fully by Haass, Boomer and Morris on ${ }^{6}$. The additional systems studied were ortho-, meta-,and peraxylene,propyl-benzene and methylcyclohexane with hydrogen bromide. The conolusion was draw that the benzene nucleus, whether in benzene or 1t's alksl substitution products, has an outer field of force with definite tendency to attract hydrogen bromide molecules. This force, however, oan only come into play when the secondary valence is not such as to 
attract molecules of it's own species. There is greater attraction between molecules of the same species if they are symmetrical than there is between those molecules and hydrogen bromide. Whether or not a molecular compound is formed depends on which of the three attractive forces below predominatea.

(1) The force between hydrocarbon and hydrocarbon.

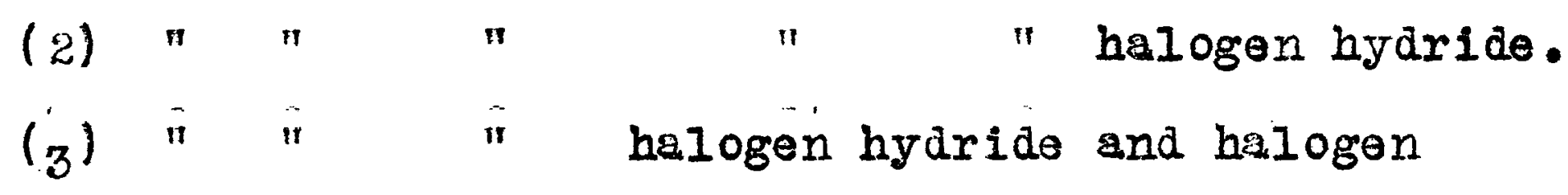
hydride.

Physical properties such as melting point are a criterion of force (I) and show that there is notable variation with different hydrocarbons. Since hydrogen bromide was presentin all systems, whether or not molecular compounds were formed, force $(3)$ is considered small. Force(2) appears to be independent of the hydrocarbon as long as the benzene nucleus is present. Consequently if foroe (i) is relatively small there is a great likelihood of molecular compound formation taking place.

The fact that unsaturation in such hydrocarbons is the cause of theirattraction is strikingly demonstrated. Methyloyclohexane showed no formation of molecular compounds with hydrogen bromide even though it's freezing point is below that of toluene, the corresponding aromatio hydroosrbon. 
As a final conclusion it is stated that unsaturation definitely causes molecular compounds to be formed and that fallure to form such compounds in spite of unsaturation is due to the relatively great attraction of molecules of the same species for oneanother.

Turning to the aliphatic hydrocarbons Hass and Wright investigated their ability to form molecular compounds. Ethylene wa found to form no moledular compound with hydrogen bromide while the reverse is true for propylene. This appears to be more evidence in favor of the conclusion of Mass and Russell 5 who showed that the more symmetrical the molecule may be the less will be it's attraction for hydrogen bromide and consequently the grester will be the force of attraction between molecules of $1 t^{\prime} s$ own species.

Considerable correlation of the physioal propertios of hydrooarbons with their velooities of reaction have been made in this laboratory.

It was noticed by Mass and Russell in the ir investigations on ungaturation and molecular compound formation that those substances that formed molecular compounds showed signs of chemlas reaction on being allowed to stand at room temperatures. No such reaction was found in the oase of hydrocarbons which did not form these compounds. Thus, al though benzene and acetylene do not react with hydrogen bromide, the subst1tuted benzene and allylene show definite signs of reaction. 
Continuing on the same 1 ine Maass and Wright ${ }^{8}$ showed no reaction to take place with ethylene while propylene follows allylene in it's beheviour in that it does react and secondary products are formed.

Maass and Siveritz ${ }^{9}$ investigated the reaction velocity between hydrogen chloride and propylene quite thoroughly. One of the most important facts brought out was that propylene and hydrogenuchloride do not react in the gaseous state under normal conditions of temperature and pressure. From the point of view of attractive forces between the molecules this is easily inderstandable since it is to be expected that the influence of these forces upon reaction velocity, while they may be all important in the liquid state where the molecules are within range of their attractive forces, will become a very minor factor in gaseous reactions.

Further corredation of physical properties of hydrocariv bons with velocity of rerctionwas made by Coffin and Mass ${ }^{10}$. The three butylene isomers offered such field for investigation and the velocity of reaction of these isomers with hydrogen chloride was determined. It was found that $r$ butylene reacted almost instantaneously with hydrogen chloride at $-78.5 \mathrm{C}$. The more symmetrical isomers reacted much more slowly and were proved to be homogeneous in the Ilquid state. No reaction occurred with $\alpha$ and $\beta$ butylenes in the gaseous state but with $\gamma$ butylene a slow heterogene ous reaction took place. From the curves of reaction velocity there was evidence of a secondary reaction similar to the case of propylene. 
The results of all these investigations pointed to the importance of molecular attraction in both molecular compound formation and velocity of reaction. The magnitude of such forces is grestest in condensed systems although not entirely absent in the geseous phase.

In the hydrocarbons of the saturated methane series the primary valencies of carbon and hydrogen neutralize one another to such an extent that the residual forces are very small. However in the unsaturated etrylene and acetylene series the primaty valences are not satisfied to the same extent resulting in an increase of the residual valence depending on the structure of the molecule. The compounds, especially the elementary members, offer an exoellent opportunity for the study of the fundamental forces that oome into play in the molecule.

The work to be described in this thesis had for it's object the investigation of the magnitude and nature of the forces existing betwe on like molecules in so far as these forces oan be determined by examining their effect on physical properties which kinetic theory tells us are influenced by the attraction of molecular aggregates.

A large number of the physical properties of compounds containing two and three oarbon atoms have heen determined in th this laboratory by Masss and Wright ${ }^{8}$. The four carbon butylenes and butanes were investigated by Coffin and Mass ${ }^{10}$. The work to be described below deals with the extension of this investigation to the four carbon hydrocarbons of the acetylene series along with other members of this homologous serles. 
Beside the interest attached to the homologous relationship existing between these compounds and those containing two and three carbon atoms the fact that structural isomerism makes it's apperance lends further signiffoance to the work.

The preparation and purification of methyl, ethyl, propyl and dimethyl acetylene are described. The vepor pressures, densities and surface tensions accurately determined over a range of temperature are described and tabulated together with the melting points and oritical temperatures. Constants calculated from these data such as Molecular surface energy, total surface energy,parachor etc. are also included. Great atress was la1d on the purity of the compounds and the accuracy of the measurements since small differences in physical properties were to be expected in the case of the isomeric substances. The properties investigated are discussed from the point of view of modern theories of molecular orientation and attraction. Homologous relationships are considered as well as the effect of carbon chain structure on physical properties. 
The determination of the physioal constants and their interpretation in terms of physical chemioal theories was the prime object of the researoh. This is dependant on establishing the purity of the compounds examined and it is well to emphasize this once more. As a consequence the methods ohosen for the pweparation of the compounds were based on obtaining purity at the expense of any experimental complications no matter how involved. The methods of preparation were therefore investigated from the point of view of how each step might possibly affect the purity of the product. This in 1tself mag be lookd upon as one of the most important features of the work to be deseribed as it undoubtedly was the time consuming element in this investigation. Many subsidiary changes in experimental technique which were found necessary are not described and their existence solely mentioned at this stage to indioate the importance attached to a method of preparation whioh ensures a product that can be definitely brought to a high state of purity. 
The Preparation and Physioal Properties of Methyl-, Ethyl-, Propyl- and Dimethyl-acetylene.

In order that the aliphatic acotylenes to be investIgated would be attainable in the highest possible form of purity the method adopted for their preparation was that of direct synthesis from the simple constituents of each compound. This method, with certain modifications, is that used originally by Iebeau and Picon ${ }^{11}$ and consists in the alkylation of sodium acotylide in liguid ammonia as a resction medium.

The general proce fure was to melt a suitable quantity of sodium in an atmosphere of hydrogen and straining 1t while molten through a porous plate to remove the oxide adering to 1t's surface. It was then dissolved by liquid ammonia and acetylene bubbled through the blue solution until disappearance of color indicated the complete formation of sodium acetylide which seperated out in the form of white crystals. The alkyl iodide was then added and the reaction allowed to take place after whioh separation of the desired alkyl acetylene from ammonia was effected through removal of the latter by passing the mixture of gases through sorubbers filled with water and dilute sulphuric ac1d. The acetylene compound was then collected by conden- 

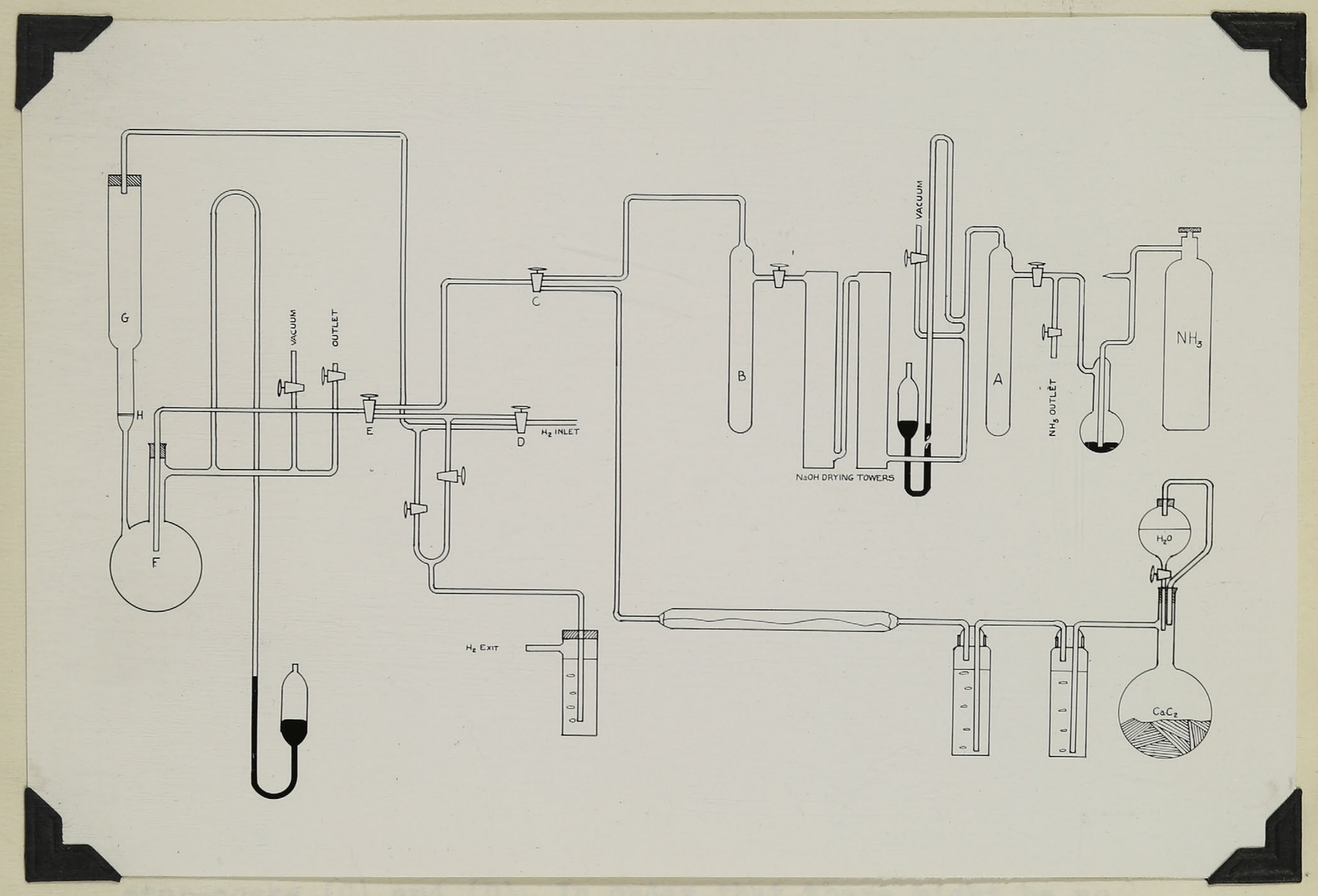

rige 2 
sation in a tube cooled with a carbon-dioxide ether mixture. This product was subjected to further purification by a system of fractional distillation to be described below. All reagents, hydrogen, ammónia, scetylene and alkyl lodide were carefully purified and dried before use. An all gless apparatus which eliminated contamination of the reactants from water vapor and oxygen of the air was constructed and is represented diagramatically in Figure: 1 .

Most of the air was removed from the apparatus by evacuation and flushing out with hydrogen which was obtained from a Kipp generator and purified by passing it through sodium hydroxide solution, concentrated sulphuric acid and finally over phosphorus pentoxide in order to remove hydrochloric soid and water. Then a sultable amount of sodium was welghed out and dropped into the large pyrex tube (G). The entire apparatus was thoroughly washed out with hydrogon by allowing the gas to flow through the apparatus first in one direction then in the other by manipulation of the stop-cocks (C) and (D). In order that there might be no air in the appar atus due to leaks around the rubber stopper at the top of tube $(G)$ the hydrogen flowing out of the apparatus was allowed to bubble under the pressure of a small height of water in a wash bottle as seen in the diagram. After the hydrogen passed through for about two hours and 
no oxygen remained in the apparatus, as was indicated by testing a sample of the emitted gas, tube (G) was heated with a free flame, the stream of hydrogen being directed so that it would force the sodium, when molten, through the perforated plate (H). When the purified sodium was in the bottom of the flask (F) the large tube was sealed off. The ammonia used was obtained from a cylinder of pure anhydrous ammonia and was further purified by liquifying it in tube (A) which was cooled by a carbon-dioxide ether mixture contained in a dewar flask. The rate of flow of ammonia was first regulated by observing the rate of bubbling through a mercury trap and the extent of condensation followed by a manometer connooted to the system. The liquid ammonia in (A) was then purified by allowing some of it to boil off and the midale fraction passed through drying towers of sodium hydroxide to be recondensed in (B). It was then used to dissolve the sodium by condensing it in llask (F). The rate of condensation was followed by second manometer connected with the system as shown in the diagram. Subsequent experiments showed the ammonia from the cylinder to be anhydrous and of sufficient purity so that it was used to dissolve the sodium direotly and was not subjected to fractionation. About three hundred cubic centimeters of Iiquid ammonia were put in (F) forming an inky-blue solution. 
Acetylene from a Prest-O-Iite cylinder was first used but was found to contain a large quantity of acetone and consequently acetylene was prepared and purified as follows.

Water was dropped on pure calcium carbide previousIy treated with ninety eight percent ethyl aloohol to diminish the intensity of the reaction. The acetylene so generated was passed through wash bottles of sodium hydroxide and chromic acid to remove carbon dioxide and phosphine. It was passed through a phosphorous pentoxide tube to remove water vapor and then allowed to bubble vigorously in to the blue solution so that the sodium acetylide formed would not clog up the tube leading into the ammonia. The end point was given by a change of color from blue to white. Fxcess acetylene,dissolved in the ammonia, was remored by distilling off some of the ammonia and replacing it with the pure liquid so as not to form too viscous a mixture.

The alkyl iodide was freshly distilled and slightly less than the calculated quantity, based on the amount of sodium put into the llask, was used so as to avold contamInating the produet with a volatile impurity. When this amount of lodide had been added slowly and the reaction mixture shaken from time to time the contents of the flask were allowed to stand to enable the reaction to proceed as nearly as posible to completion. 
$-214-$

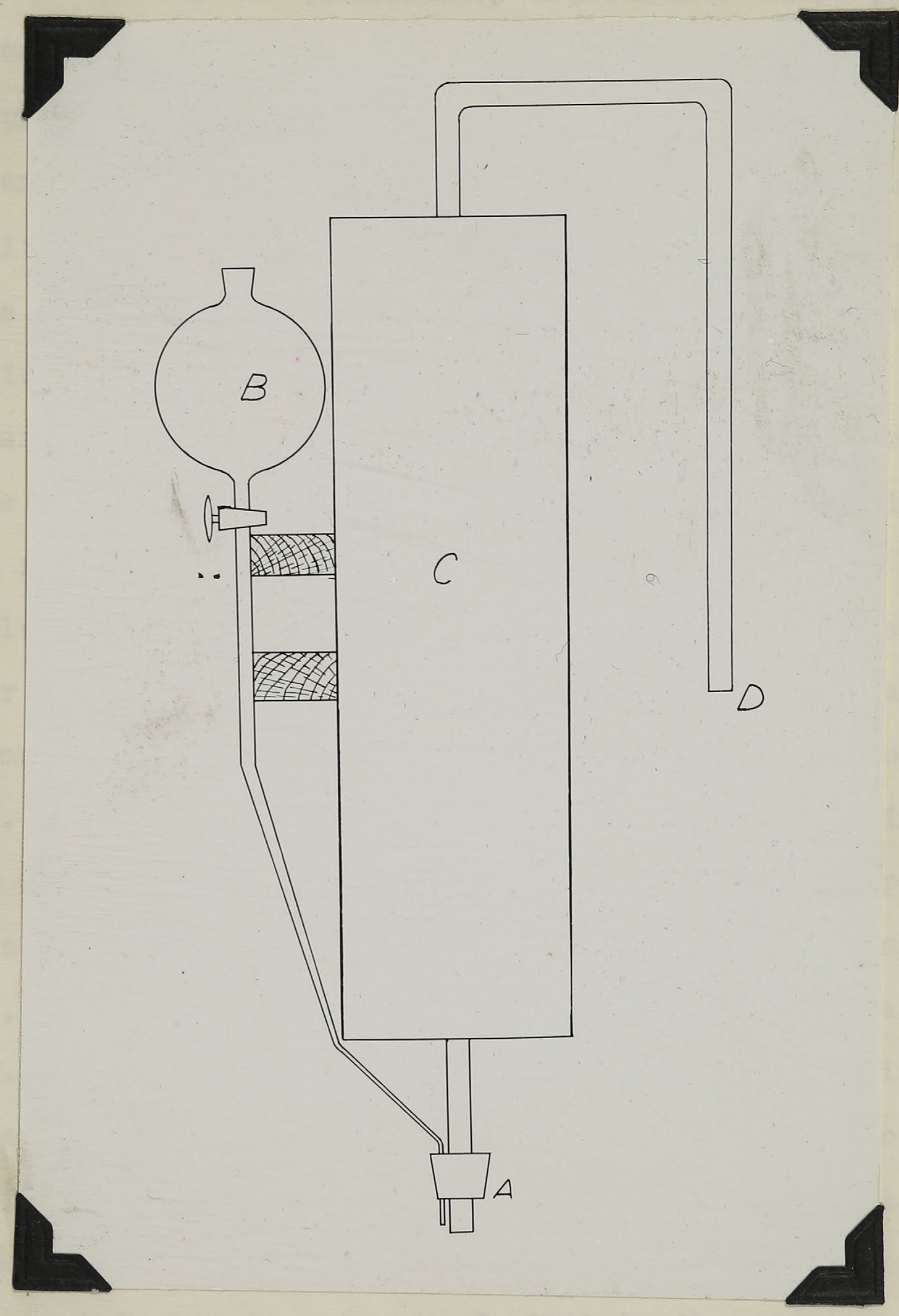

Fig. 2 . 
In some of the premiminary experiments where poor yields were obtained,especially in the preparation of ethyland propyl-acetylene, since the reaction between the alkyllodide and sodium acetylide might be expected to take place with a little more difficulty, the alkyl-iodide was dropped Into the liquid ammonia containing the sodium acetylide in suspension while the mixture was being refluxed under atmospherio pressure at the highest possible temperature i.e. the boiling point of liquid ammonia $-38^{\circ} \mathrm{C}$. For this operation a reflux condenser of the form shown in Figure 2 was employed. tube (D) of about one centimeter inside diameter bent in the shape of a $U$ was surrounded with a pyrex jacket (c) filled with a carbon-dooxide ether cooling mixture. Tube (D) passed through a rubber stopper fitting tightly in the bottom of $(c)$. Ieaks were prevented by pouring in a little mercury which, when frozen by the cooling mixture,completely topped all leakage around the rubber stopper. Attached to (O) was a dropping funnel for addition of the alkyl iodide. The rubber stopper (A) fitted into the top of flask (F) when the tubes used for the introduction of the ammonia had been removed. Refluxing the reaction mixtufe in this way in order to facilitate the reaction also served the purpose of removing the excess actylens. which was dissolved in the ammonia. In order that no water vapor might enter the apparatus during this part of the 


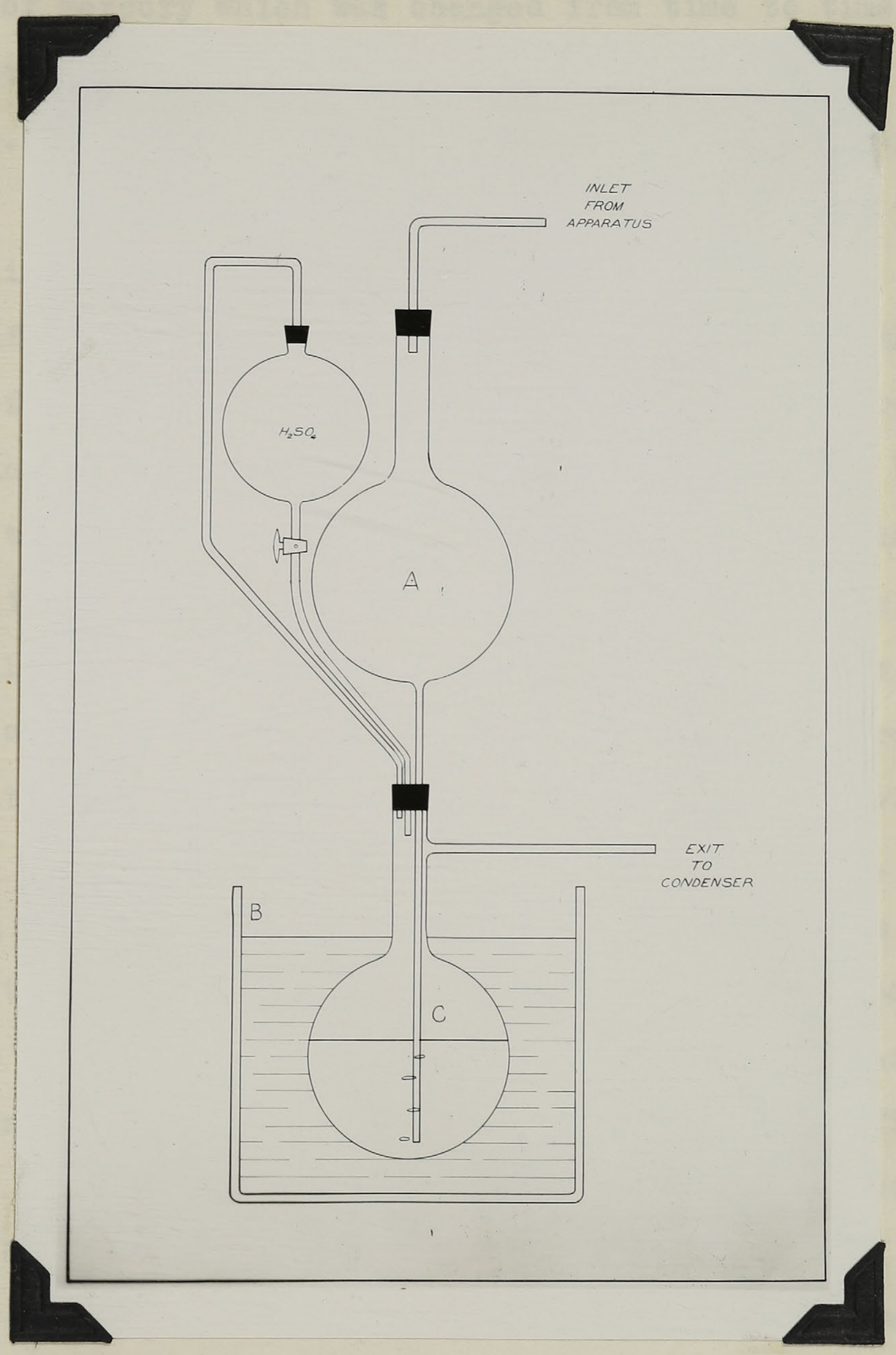

Mg. 3 . 
preparation the exit to tube (D) was placed under a small quantity of mercury which was changed from time to time to prevent the possibility of forming too much meroury acetylide. The reaction mixture was refluxed in this way while the alkyl lodide was being added very slowly and the time required was usually two or three hours. After the reaction was thought to be complete the mixture of ammonia and alkyl acetylene was passed through a scrubbing apparatus as show in Fig. 3. The gases were boiled off from the reaction flask and passed through a solution in (C) maintained slightly acidby means of the dropping funnel filled with sulphuric acid. In case the contents of (C) were suddenly sucked back the bulb (A) served to prevent contamination of the reaction mixture with water and acid. The alkyl acetylene,being insoluble in the dilute acid, passed on and was dried by passing it through a calcium chloride tube previous to condensation in a storing tube cooled to $-78^{\circ} \mathrm{C}$ by a carbon-dioxide ether mixture contained in a dewar flask. This more or less crude product was finally subjected to purification by a system of fractional distillation to be described below.

Since apecial modifications for each compound were found to be necessary for their preparation a description of the preparation of Methy1-, Ethyl-, Propyl- and Dimethylacetylene will be given below under separate headings. 


\section{Methyl Acetylene.}

Methyl acetylene was prepared and it's properties studied by Wright and Maass ${ }^{7}$ but since the method of purification used by Coffin and Mass ${ }^{10}$ in the investigation of the butylenes and butanes was a marked improvement over the former method where small amounts of material were concerned the preparetion of methyl acetylene was undertaken to see if, when purified in this way, the results of Wright and hass would be confirmed or not.

The preparation of methyl acetylene was carried out In the panner described above. Since this is the first of an homologous series of mono-substituted acetylenos, as would be expected, reaction between the methyl lodide and sodium acetylide took place most easily even at temperatures below the boiling point of liould ammonia so that in the preparation of this compound it was found to be unnecessary to use the refluxing apparatus for promoting the reaction. The mixture of ammonia and methyl acetylene was passed through a large quantity of water and then through dilute sulphurio acid thus removing the ammonia completely and allowing the methyl acetylene, which is a gas at ordinary temperatures, to be oollected by condensation.

Several experiments were made on the preparation of methyl-acetylene to determine what method would produce the maximum yield. Two samples of methyl-acetylene were prepared. The first wes obtained without the use of the ao1d separator and the product in this oase wes considerably less than that resulting when the mixture of gases was 
allowed to pass through the ac1d solution. Measurements made for vapor pressures and density, to be found in the tables below, on both samples were found to check each other.

\section{Ethyl-acetylene.}

Ethyl-acetylene was also prepared twioe with slight ahanges in the method of proce dure. In the first preparation it was never in contact with an aold modium which might have polymerized 1t. In the second preparation where better Jields were obtained, by the use of the aold separator, the ethyl-acetylene was in contact with aold both in the separator and also during passage over phosphorus pentoxide for removal of small traces of water. Although propylene polymerizes ${ }^{7}$ on being passed over phosphorous pentoxide ethyl-acetylene does not appear to do so since the vapor pressures and boiling point were found to be the same whether it did or did not come into oontaot with an acid medium.

The useful information was therefore obtained that no secondary products are formed by passing the ethylacetylene through dilute sulphuric acid or,after remoral of most of the water by chilling and filtering off the ethyl-acetylene,by passing it over phosphorous pentoxide. 


\section{Propyl-acetylene.}

In the preparation of propyl-acetylene the method of proce dure given above was followed throughout. The mixtore was refluxed while the propyl lodide was being added and the propyl-acetylene freed from ammonia by means of the acid separator. Final purification was effected by the method to be described below.

\section{Iso-propyl-acetylene.}

Experiments were made in an attempt to synthesize 1so-propgl-acetylene by the same method making use of the reaction between sodium acetylide and isopropyl lodide but no product was obtained. The reaction between a branched chain lodide and sodium acetylide doos not give the corresponding isopropyl-acotylene but a straight chain etaylenic compound according to the equation: 12

$\mathrm{CH} \mathrm{CNa} \quad 1-\mathrm{C}_{3} \mathrm{H}_{7} \mathrm{I} \quad \mathrm{NaI} \quad \mathrm{CH}: \mathrm{CH} \quad \mathrm{CH}_{3}-\mathrm{CH}=\mathrm{CH}_{2}$ Since the hydrocarbon could not be prepared in this way for Investigation other methods were not thought suitable since they would involve the presence of impurities in the product that would be most diffioult if not impossible to remove completely to furnish a sample with the purity required for the density and surface tension measurements. 


\section{Dimethyl-acetylene.}

Dimethyl-acetylene has been prepared by Faworsky ${ }^{13}$ who heated ethyl-acetylene in a sealed tube with alooholic potash whereby rearrangement of the molecule occerred resultin the formetion of dimethyl-scet ylene.

Although this method of preparation was successful it was thought best to develop another method, if possible, in view of the fact that dimethyl-acetylene prepared in this way would contain quantities of aloohol, alkali and ethylacetyiene which would render purification of the product to the degree desired for the surface tension messurements very diffioult.

Consequently the preparation was attempted by methylation of the sodium derivative of methyl-acetylene in a manner analogous to thet used in the preparation of the other alkyl acetylenes.

A large quantity of methyl-acetylene was prepared by the usual method and passed into the blue solution of sodium in Ilquid ammonia until disapearance of the blue oolor showed complete formation of the sodium-methyl-acetylide. Since Debea ${ }^{14}$ found this reaction gave one moleoule of propylene for every two of sodium derivative formed according to the equation:

$$
3 \mathrm{CH}_{3} \mathrm{C}: \mathrm{CH}+2 \mathrm{Na} \leftrightharpoons 2 \mathrm{CH}_{3} \mathrm{C}: \mathrm{CNa}+\mathrm{CH}_{3} \mathrm{CH}: \mathrm{CH}_{2}
$$

this had to be taken into account when caloulating the final gield of dimethyl-scetylene desired. 
When all the sodium had reacted with the methylacetylene the ammonia and propylene were allowed to pass off leaving behind the white solid sodium derivative. Since the mercury and silver derivatives of methyl-acetylene are non explosive $15_{1 t}$ was deemed safe to do this.

Fresh ammonia was condensed in the reaction flask and the solid suspended as usual in the liquid. Methyliodide was added and the reaction allowed to proceed without the ald of refluxing. That reaction took place seemed to be indiosted by the change in appearance when crystalline sodium lodide settled to the bottom of the flask in the place of the pasty appearance of the sodium methylacetylide.

The dimethyl-acetylene was separated from the ammonia In the usual way and purified in the manner to be described below.

When the sample had heen purified and the measurements for surface tension and density made it was rather surprisingly found that the value for the parachor,calculated from these messurements, was over four per cent too low. Consequently the surface tension and density were age in carefully determined. No difference between these values and those previously obtained was found. This, naturally, caused considerable alarm since it indicated quite strongly that there was a possibility of this oompound not being dimethyl- 
acetylene at all but possibly some other compound formed perhaps by a rearrangement of the reactants similar to the reaction between isopropyl lodide and sodium acetylide. The next problem was to determine the molecular weight of the product. This was done by the Dumas vapor density method. The apparatus was connected to the fractionating apparatus containing the pure cokpound and consisted of a large bulb of about $400 \mathrm{cc}$. capacity maintained at a constant temperature by means of a water bath. Attaohed to the bulb were a manometer and three amall glass bulbs connected to the apparatus in such a way that they could be readily sealed off. The method of proceedure was to fill the standard volume at known temperature and pressure with a sample of the gas whose molecular weight was to be found. Then, after evacuating the tubing connecting the small bulbs with the standard volume, the gas in the latter was condensed in one of the small bulbs by means of a cooling pixture. The small bulb was then sealed off and we1ghed. When the welght of the gas was found and various corrections applied the molecular weight was found according to the following equation:

$$
P V \quad-\frac{W}{m} R T
$$

where :

$$
\begin{array}{lll}
\text { P Pressure, } & \text { m Moledular weight. } \\
\text { V Volume of gas. } & \text { R Gas constant. } \\
\text { w Weight of gas } & \text { T Mbolute temperature. }
\end{array}
$$


Three determinations were made at different pressures and the molecular weights so obtained plotted against pressure. The results were extrapolated to zero pressure and 1 was found that the extrapolated value agreed with the theoretioal molecular weight within one per cent. Now the problem was to determine whether or not the compound was actually an acetylene or some isomer containing a pair of double bonds. The possible isomers are the two butadienes and ethyl-acetylene.

The bolling pointe of the butadienes are given in the International Critical Pables as 1980C. for the 1.2 butadiene and $-2^{0} .6 \mathrm{C}$. for the 1.3 butadiene. The boiling point of ethyl-acetylene has been found to be 8.6 C. Since the boiling point of the product thought to be dimethyl-acetylene was found to be $27.1 \mathrm{C}$. and agrees with the value found by other investigators ${ }^{16}$, $27^{0} .2-27^{0} \cdot 6$, it was not considered linely that the produck could be any one of these 1somers but as a final check the tetrabrom compound was made and analysed. Faworsky ${ }^{17}$ has prepared dimethyl-acetylene and studied 1t's bromination products. He obtained the fully saturated 2.2 .3 .3 . tetrabrombutane from dimethyl-acetylene and studied 1t's properties. His method of bromination was followed as far as possible.

few drops of bromine were added to the pure 
compound cooled in toe until a permanent bromine color was obtained. According to the above mentioned article 2.2.3.3. tetrabrombutane separated out of the reaction mixture on adition of the equivalent amount of bromine. but in this instance this did not seem to ocour. Consequently the reaction mixture was put in a quartz tube and exposed to ultra-violet light. In a very short time white crystals began to appear and after several hours bromination had gone to completion. Considerable difficulty was experienced in handing this compound since either the tetrabrom or the intermediate dibrom exhlbited very powerful lacrimatory properties. However the compound was crystallized a number of times from petroleum ether and a ample obtained that was thought to be of sufficlent purity to analyse.

Faworsky found the melting point of 2.2.3.3. tetrabrombutane to be $230^{\circ} \mathrm{C}$ and the melting point found by the author was in the vioinity of $210^{\circ} \mathrm{C}$. the disorepancy between this and Faworsky's value being due possibly to a small amount of impurity. That this bromination product could not be obtained from one of the isomers mentioned above can be seen from list of the properties of the following tetrabrombutanes. ${ }^{18}$ 
1.1.2.2. Tetrabrombutane (from ethyl-300tylene) sublimes at $200^{\circ} \mathrm{C}$. without melting.

1.1.4.4. Tetrabrombutane is an oil . B.P. $138-145^{\circ} \mathrm{C}$.

$1.2 \cdot 2.3$

$n$

is 11 quid at $-17^{\circ} \mathrm{C}$.

1.2 .3 .4$.

$n$

melts about $118^{\circ} \mathrm{C}$.

As a final step in the identification of dimethylacetylene this crystalline compound was analysed for bromine. The results of analysis gave $86.6 \%$ percent bromine compared to the theoretioal 85.5\%. This seems to establish fairly well the identity of the compound as dimethyl-acetylene. The values found for it's various physiosl constants will be found in the tables below. 


\section{Purification of the Hydrooarbons.}

The crude alkyl acetylene, after having been separated from ammonia, was subjected to final purifioation as followg.

For the removal of traces of water from the crude product before fractionation the method of drying was thet used in the purification of the butylenes and butanes by doffin ${ }^{10}$. Briefly this consists in condensing the hydroarbon in a tube to the bottom of which attaohed a oapillary tubing plugged with glass wool and leading to the top of another tube eracuated and cooled to $-78^{\circ} \mathrm{C}$. When the first tube oontaining the hydrocarbon is chilled by a cooling mixture the water separates as crystals which adhere to the sides of the tube. After the stop-cook, leading into the evacuated tube, is opened the hydrocarbon is strained through by it's own vapor pressure. In this way the liquid hydrocarbon is separated from the water which remains frozen to the sides of the glass tube or is filtered out by the glass wool plug at the opening of the capillary. This method has been found to be muuch more effective than distillation for removing water.

When the product had been freed from water in this way it was transferred to the fractionating apparatus Fig. 4. 


$$
(I I)
$$


Th1s consisted of a large reservoir (R) equipped with a magnetic stirrer and connected to a system of manometers and recelving bulbs as shown in the diagram. The liquid in (R) was kept at about $-50^{\circ} \mathrm{C}$. by means of an aoetone bath cooled with solid carbon dioxide and stirred vigorously with the magnetic stirrer. The receiving bulb, into which the Praction was being distilled, was cooled to $-78^{\circ} \mathrm{C}$. with a carbon dioxide ether mixture. Under these conditions distillation proceoded slowly and a very satisfactory fractionation obtained. By means of the manometers vepor pressures of any fraction or of the residue in (R) could be determined. Vapor pressures were measured at appropriatIy fixed temperatures for each hydrocarbon.and were maintainod with a carbon dioxide ether bath atirred with a cureent of dry air bubbles.

Purifioation of the liquid was sccomplished by distliling from a fraction with a low to that with a high vapor pressure. The final heads and tails, consisting of impurities with very high or very low vapor pressures, were rejected. When finally several fractions having the same vapor pressures were obtained they were united and subjeoted to refractionat1on. If the same vapor pressures were obtained as before for each fraction the Ilquid was assumed to be purified and was then used for identifiogtion tests after which it's physioal constants were determined. The hydrocarbons were distilled into the dilatometer, oapillarimeter and melting point tube which were then sealed off from the apparatus. 
Phys10al Propertios of the Hydrocarbons.

The temperature baths used in the determination of the densities, surface tensions, vapor pressures and molting points consisted of a liquid, suitable for the temperature range under which the observations were being carrled out, contained in a transparent dewar flask. All baths were kept vigorously stirred with a ourrent of dry air bubbles and temperatures measured with standard thermometers to an accuracy of one tenth of a degrea. It may be noted that all distillations and measurements were made in the absence of air and moisture and gless sealed connections used throughout.

Solid carbon dioxide was used as the oooling agent from $0^{\circ} \mathrm{C}$. to $-78^{\circ} \mathrm{C}$. The bath orer this temperature range consiated of acetone or ether. For the measurement of properties at lower temperatures high test gasoline was used with liquid air as a cooling agent in a manner to be describod later. It was found by previous experimenters that when us 1 ing ether as a cooling bath it is best to add about twenty por cont alcohol. Water is insoluble in pure ether at low temperatures so that moisture condensing from the atmosphere renders the latter opaque. The aloohol ether solution on the other hand dissolves considerable quantities of water even at $-80^{\circ} \mathrm{C}$. 


\section{(i). Density.}

The densities of the liquid hadrocarbons over a temperature range suitable for each were messured by the dilatomeitr method. The dilatometer consisted of a thick walled glass bulb serled to the and of $a_{1}$ capillary tube of uniform bore. After thoroughly evacuating the apparatus the hydrocarbon was distilled into the dilatometer which was sealed onto the fretionating apparatus. When a sufficient quantity had been condensed by cooling with carbon dioxide ether mixture the dilatometer was sealed off just above the capillarg.

The volume of the dilatometer for different positions of the meniscus in the capillary wa accurately determined by finding the weights of ter,at a fixed temperature, that occupied the different positions on the stem. Volumes were determ: ined for three positions of the meniscus and graph mede plotting volume against height of the meniscus. A reference mark etched on the side of the capillary served as a zero mrk from which readings were mide. All measurements of heights were determined by means of an sccurate cathetometer.

After filling the dilatometer with the hydrocarbon under investigation and sealing it off, the height of the meniecus in the caplilary was then measured over the desired temperature range, bulb and capillary being entirely immersed 
In the temparature bath. The dilatometer was then allowed to come to room temperature and weighed. After cooling again the tip was broken off, the liquid removed, ary air passed through the bulb and the latter weighed. The proper correctIon was made for the wight of air and the weight of the hydrocarbon was accurately known. The volume occupied by the Ilquid at various temperatures was given by the positIon the menisous occupled in the capillary which, together with the bulb had beon accurately calibrated. This volume was further corrected for the coefficlent of expansion of the gless.

Th1s method of determining density is very accurate the probable error amounting to less than one part in two thousand. The densities of methyl-, ethyl, propyl- and aimethyl-aoetylene over the temperature range suitable for each one are given in Table 1.

The densities of Ethyl- and Methyl-acetylene were determined in duplioste on two samples prepared separately from the start but differing slightlyas mentioned above In the method of purification. The results obtained with Preparation 1 are from the sample that had never been in conteot with an aold solution or phosphorous pentoxide while those for preparation 11 are from the sample that was passed through the aold solution and over phosphorous pentoxide. Both sets of data are seen to agree. 
Table 1

Densities of Methyl Acetylene.

Preparation 1.

\begin{tabular}{ll} 
Temp. ${ }^{\circ}$ C. & Dens1ty \\
\hline-14.4 & 0.6617 \\
-17.5 & 0.6652 \\
-22.7 & 0.6710 \\
-26.5 & 0.6759 \\
-32.5 & 0.6827 \\
-36.8 & 0.6873 \\
-42.4 & 0.6936 \\
-47.4 & 0.6992 \\
-53.1 & 0.7065 \\
-57.0 & 0.7109
\end{tabular}

Preparetion 11. Temp., ${ }^{\circ} \mathrm{C}$. Density

$\begin{array}{ll}-0.5 & 0.6447\end{array}$

$-12.7 \quad 0.6582$

$-24.2 \quad 0.6711$

$-33.0 \quad 0.6814$

$-40.9 \quad 0.6911$

$\begin{array}{ll}-51.9 & 0.7039\end{array}$

Densities of Ethyl Acetylene.

Preparation I

\begin{tabular}{rr} 
Tomp., ${ }^{{ } \mathrm{C} .}$ & Density \\
\hline-28.0 & 0.7095 \\
-20.0 & 0.6997 \\
-15.0 & 0.6949 \\
-10.5 & 0.6900 \\
-5.0 & 0.6836 \\
-0.3 & 0.6784 \\
5.6 & 0.6706
\end{tabular}

Preparation 11.

Temp., " C. Density

$-31.3$

0.7119

$-23.0$

0.7028

$-11.0$

0.6899

$-0.2$

0.6784

8.9

0.6685 
Densities of Dimethyl Acotylene.

\begin{tabular}{ll} 
Temp., ${ }^{O_{\mathrm{C}}}$ & Density. \\
\hline 5.0 & 0.7102 \\
10.0 & 0.7049 \\
15.0 & 0.6997 \\
20.0 & 0.6946 \\
25.0 & 0.6894 \\
30.0 & 0.6845 \\
\hline
\end{tabular}

Densities of Propyl Acetylene.

\begin{tabular}{ll} 
Pemp., ${ }^{\circ} C_{0}$ & Dens1ty \\
\hline 5.0 & 0.7021 \\
10.0 & 0.7021 \\
15.0 & 0.6966 \\
20.0 & 0.6915 \\
25.0 & 0.6863 \\
30.0 & 0.6812 \\
35.0 & 0.6762 \\
40.0 & 0.6719 \\
45.0 & 0.6664 \\
\hline
\end{tabular}

A graphioal representation of all these results will be found in Figure 5 . 


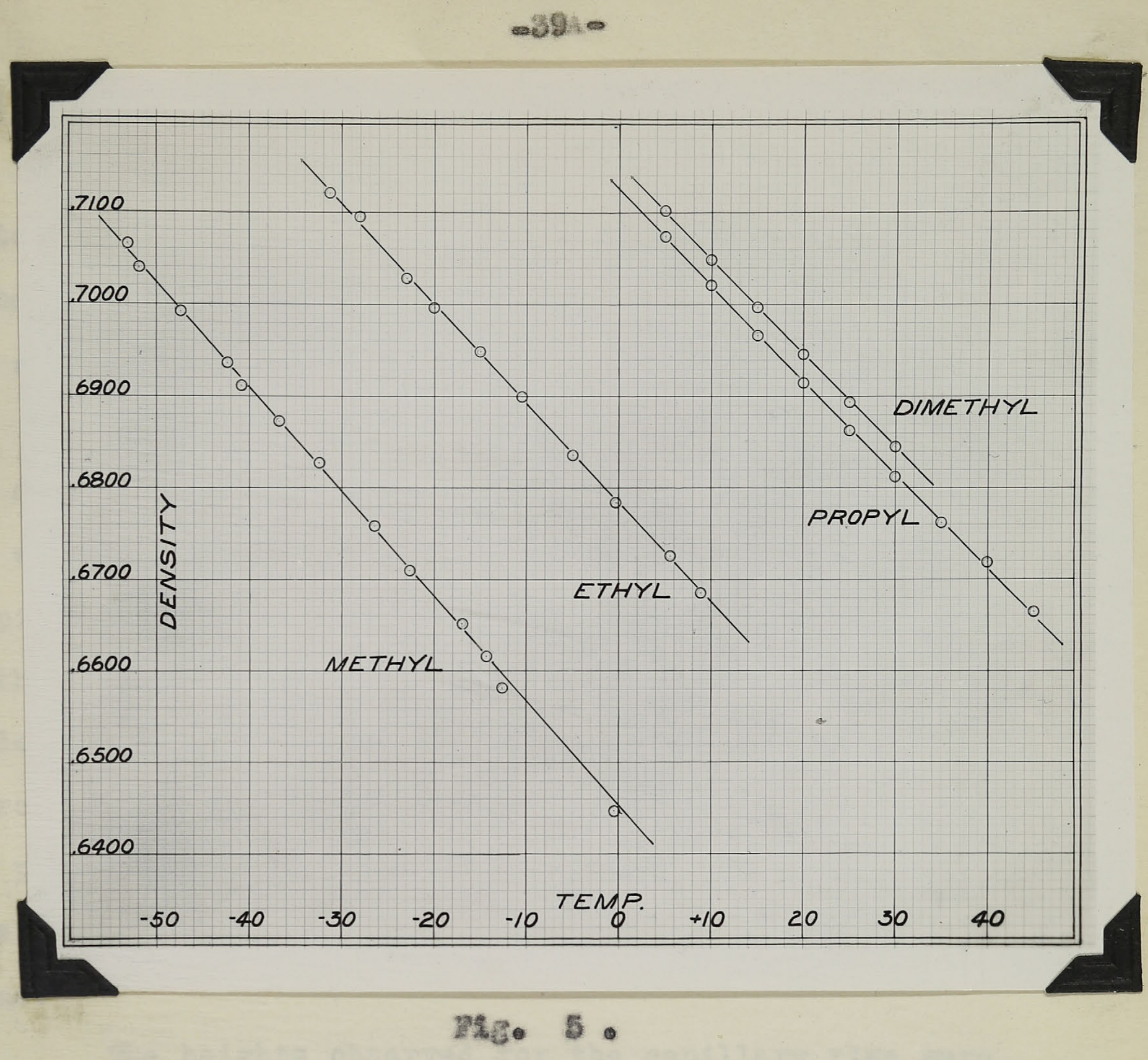




\section{(ii) Surface Tension.}

The sufface tensions of the hydrocarbons were determined by the oapillary rise method using the type of tube reoommended by Richards ${ }^{19}$ the capillary being attached as a side arm to the tube.

The oapillarimeter was filled with the hydrooarbon by distillation and then sealed off from the apparatus. It was entirely immersed in the temperature bath and the capillary rise measured at various temperatures with a cathetometer. Observations over the temperature range were made at least twice for each hydrocarbon and readings made through different parts of the tube to aroid errors due to parallax. The capillarimeter was maintained in a vertical position by lining it up from time to time with a plumb line.

The heights observed for the capillary rise were plotted against temperature on a large soale graph. At appropriate temperature intervals the ospillary rise was taken from the curve so obteined and these values introduced into the oaloulations. The expression relating capillary rise, and density is given in the following equation:

$$
s=k \cdot d \cdot h
$$

where :

$$
\begin{aligned}
& s=\text { Surface Tension. } \\
& k=\text { Constant of the Capillarimeter. } \\
& d=\text { Density. } \\
& b=\text { Capillary rise. }
\end{aligned}
$$


The density was obtsined for the necessary temperatures

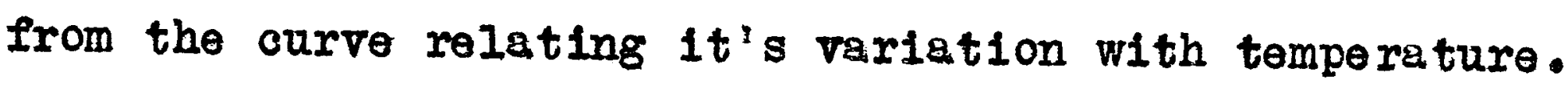
The remaining factor, $K$, the constant of the capillarimeter, was obtained by calibrating the capillarimeter with pure ether whose surface tension at 20:0C. 1s accurstely known. (17.I dynes). The density of ether is given by the following expression :

$$
\mathbf{P}_{t}=\mathbf{P}_{\mathrm{s}}+10^{-3} \mathrm{a}\left(\mathrm{t}-\mathrm{t}_{\mathrm{s}}+10^{-6} \mathrm{~b}\left(\mathrm{t}-\mathrm{t}_{\mathrm{s}}{ }^{2}\right. \text {. }\right.
$$

where:

$$
\begin{aligned}
& \mathbf{P}_{\mathbf{t}}=\text { Density of ether at } \mathbf{t}^{0} \mathrm{C} . \\
& \mathbf{P}_{\mathbf{s}}=\text { Constant } \quad .73629 \\
& \mathbf{a}=" \quad-1.1138 \\
& \mathrm{~b}=" \quad-1.237 \\
& \mathbf{t}_{\mathbf{s}}=0^{\circ} \mathrm{C} .
\end{aligned}
$$

From this equation the density of ether was found to be 0.7135. The capiliary rise for ether was measured and, knowing the density and surface tension for ether at 20:0 C. the constant $\mathrm{K}$ for the oapillarimeter was obtained.

The surface tensions and molecular surface energies of the hydrocarbons are listed below in Table 2. The surface tensions of all the hydrocarbons were plotted against temperature and are represented for purposes of comparison in Figure 6. 


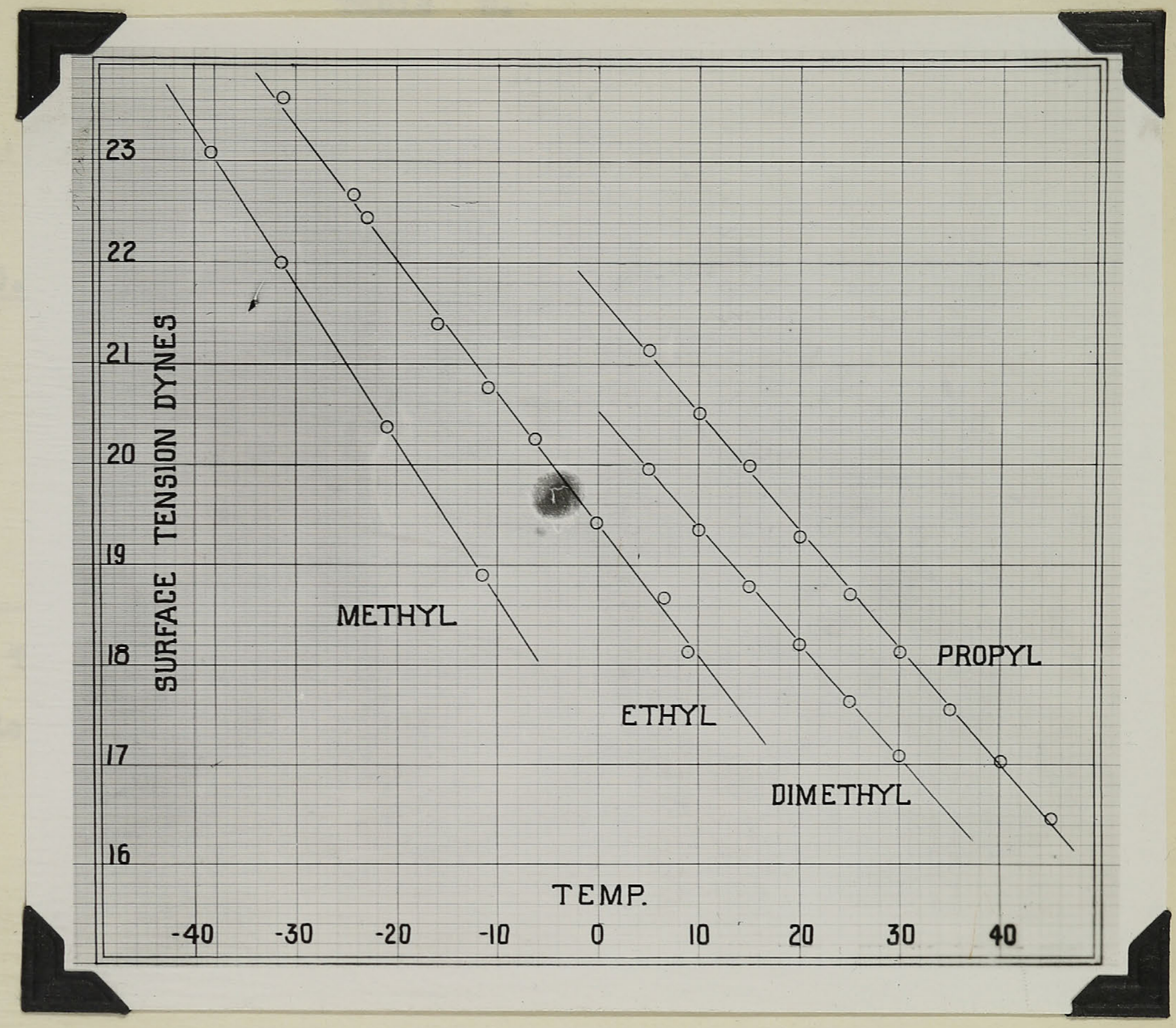

II. 6 


$$
-42-
$$

Table 2.

Surface Tension of Methyl cotylene.

Preparation II.

Temp. ${ }^{\circ} \mathrm{C}$. Surface Tension Molecular Surface Energy

$-11.5$

$-21.0$

$-31.6$

$-38.4$
18.91 dynes

20.37

22.00

23.08
293.0

312.2

332.8

346.4

The surface tension of methyl-acietylene was found only under those conditions pertaining to PreparetionII.

Surface Tension of Ethyl acetylene.

Preparation I.

Temp., ${ }^{\circ} \mathrm{C}$. Surface Tension Moleoular Surface Fnergy

$-26.3$

22.65 dynes 407.6

$-16.0$

21.40

389.3

$-6.3$

20.25

372.4

6.5

18.70

348.7 
Surface Tension of Ethyl Aoetylene. Preparation II

\begin{tabular}{lcc} 
Temp.e $\mathcal{C}_{0}$ & Surface Tonsion & Molecular Surface Energ7 \\
\hline-31.3 & 23.62 dynes & 423.2 \\
223.0 & 22.44 & 406.1 \\
-11.0 & 20.77 & 380.1 \\
-0.2 & 19.32 & 356.9 \\
8.9 & 18.13 & 338.8 \\
\hline
\end{tabular}

Surfaco Tension of Dimethyl Acetylene.

Temp. ${ }^{\circ} \mathrm{C}$. Surface Tension Molecular Surface Energy

\begin{tabular}{rll}
5.0 & 19.96 & 358.3 \\
10.0 & 19.38 & 349.2 \\
15.0 & 18.80 & 340.8 \\
20.0 & 18.20 & 331.9 \\
25.0 & 17.64 & 322.9 \\
30.0 & 17.07 & 314.0 \\
\hline
\end{tabular}

Surface Tension of Propyl Acetylene. Temp., ${ }^{\circ} \mathrm{C} . \quad$ Surface Tension Molecular Surface Energy

$\begin{array}{rll}5.0 & 21.14 & 443.5 \\ 10.0 & 20.51 & 432.9 \\ 15.0 & 19.89 & 421.9 \\ 20.0 & 19.28 & 410.8 \\ 25.0 & 18.71 & 400.5\end{array}$


Temp. ${ }^{\circ} \mathrm{C} . \quad$ Surface Tension Molectlar Surface Energy

(Propyl Acetylene Cont'd)

$\begin{array}{lll}30.0 & 18.13 & 390.1 \\ 35.0 & 17.55 & 379.8 \\ 40.0 & 17.03 & 369.7 \\ 46.0 & 16.46 & 359.2\end{array}$

(iii) Melting Points.

The melting points of the hydrocarbons were determined by the method used by Maass and Wright". Petroloum ether or high test gasoline was used as the bath liquid which was placed in a transparent dewar flask. The bath was cooled by means of liquid alr dropped into a pyrex test tube immersed in the gasoline. The liquid air, contained in another dowar flask, was forced into the test tube by air pressure. Efficient stirring of the bath was maintained by a current of dry air bubbles.

The bath was cooled until the hydrocarbon under investlgation had solidified. It was then allowed to warm up slowly the temperatures being measured with a pentane thermometer. The temperature taken as the melting point was half way between the temperature at whioh melting began and that at which the solid just disappeared. In all cases a sharp melting point was observed. The melting points are Iisted with other properties in Table 4 . 


\section{(iv) Vapor Pressures.}

Vapor pressures were determined in the fractionating apparatus for those hydrocarbons whose boiling points were below room temperature, care being taken to keep the liquid vigorously agitated in order to prevent superheating. For those oompounds having bolling points about or above room temperature an apparatus was devised coseisting of a manomoter attached to a small bulb into which the hydrocarbon could be distilled. Bulb and manometer we then sealed off from the apparatus and immersed in a bath whose temperature could be regulated. This aroided condensation of the hydrocarbon in the connecting tubing and the manometer.

For low temperatures the bath Iiquid consisted of a cerbon dioxide ether mixture stirred with a current of dry alr bubbles and contained in a dewar flask. For the higher temperatures water was used,likewise stirred with air bubbles.

In Table 3 will be found the rapor pressures of the hydroosrbons over a temperature range suitable for each. Vapor pressure curves were obtained from these data and the bolling points of the hydrocarbons taken from these curves which are to be found in Figure 7. The latent heats of evaporation, given in Table 4, were oalculated from these ourves by means of the Clapeyron equation. 


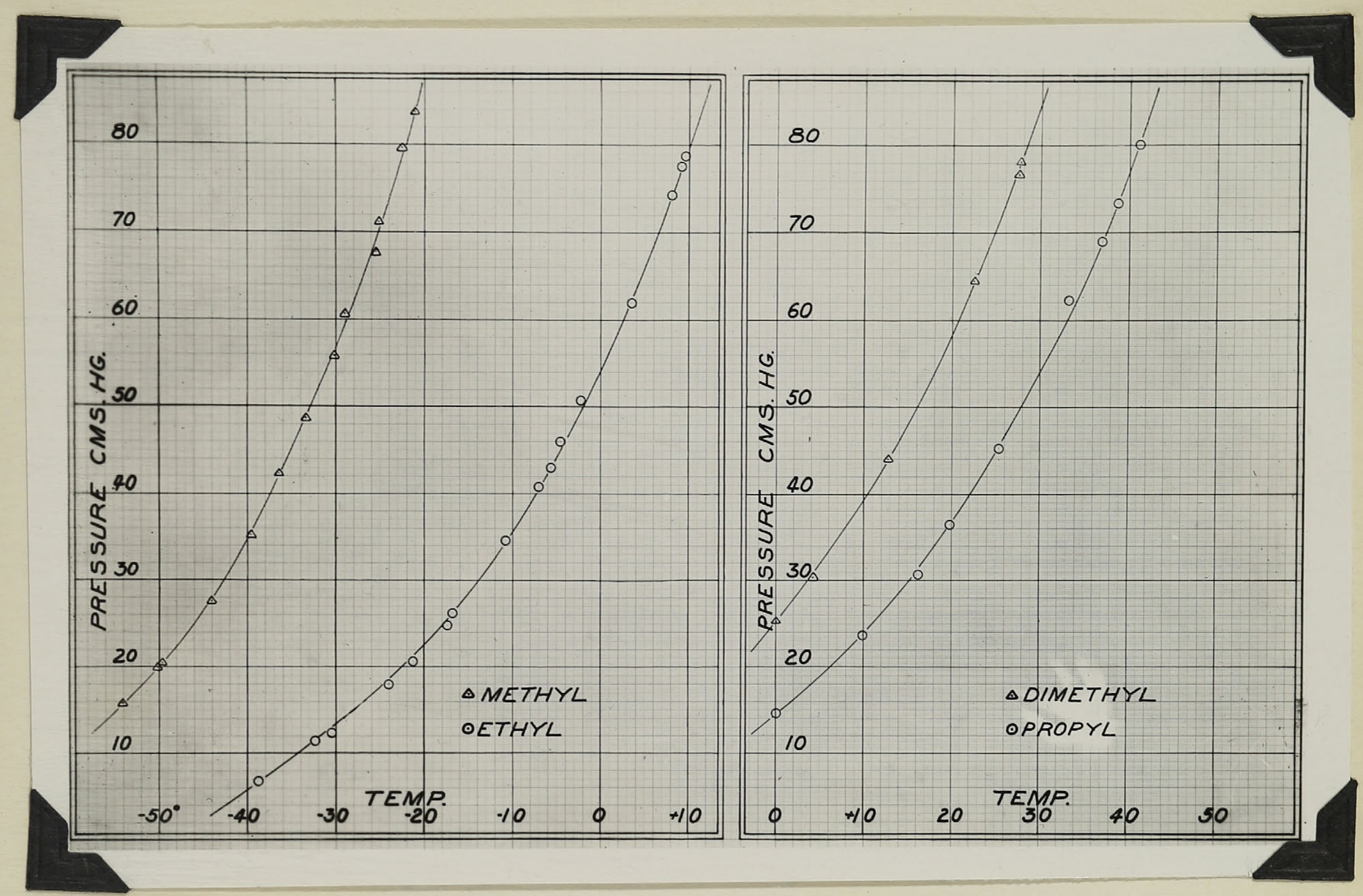

HIg. ๆ 
Table 3 .

Vapor Pressures of Methyl Aoetylene

Preparation I

Preparation II

\begin{tabular}{lccc}
\hline Temp., ${ }^{0} \mathrm{C}$. & Pressure cms. Hg. & Temp., ${ }^{\circ} \mathrm{C}$. & $\mathrm{Cms} . \mathrm{Hg} \cdot$ \\
\hline-54.1 & 15.88 & -50.1 & 20.03 \\
-49.6 & 20.46 & -39.6 & 35.18 \\
-44.0 & 27.64 & -30.2 & 55.90 \\
-36.5 & 42.17 & -25.2 & 71.15 \\
-33.4 & 48.74 & -22.6 & 80.01 \\
-28.5 & 60.80 & -21.1 & 83.80 \\
-25.5 & 67.80 & & \\
-22.5 & 79.70 & & \\
\hline
\end{tabular}

Vapor pressures of Fthyl goetylene.

Preparation I

Preparation II

\begin{tabular}{|c|c|c|c|}
\hline Temp., ${ }^{\circ} \mathrm{C}$ & Cms. $\mathrm{Hg}$. & Iomp., ${ }^{{ }^{C}}$. & Cms. $\mathrm{Hg}$. \\
\hline-38.8 & 6.80 & -32.4 & 11.46 \\
\hline$-30 \cdot 5$ & 12.38 & -24.1 & 17.93 \\
\hline-21.3 & 20.67 & $-17 \cdot 4$ & 24.81 \\
\hline-16.9 & 26.18 & -11.4 & 33.57 \\
\hline-10.8 & $34 \cdot 60$ & -7.0 & 40.85 \\
\hline-5.7 & 43.10 & -4.5 & 46.03 \\
\hline-1.3 & 50.78 & 8.0 & 74.42 \\
\hline 3.5 & 61.96 & 9.5 & 78.80 \\
\hline 9.1 & 77.66 & & \\
\hline
\end{tabular}


Table 3 .

Vapor Pressures.

Dimethyl Acetylene

\begin{tabular}{ll}
\hline Temp., ${ }^{\circ} \mathrm{C}$. & Cms. $\mathrm{Hg}$. \\
\hline 0.0 & 25.4 \\
4.2 & 30.4 \\
12.7 & 44.0 \\
22.4 & 64.5 \\
27.5 & 77.0 \\
27.7 & 78.5
\end{tabular}

Propyl doetylone

\begin{tabular}{rl}
\hline Temp. ${ }^{\circ} \mathrm{C}$. & Cms. Hg. \\
\hline 0.0 & 14.66 \\
9.9 & 23.66 \\
16.2 & 30.66 \\
19.8 & 36.50 \\
25.3 & 45.20 \\
33.2 & 62.30 \\
37.0 & 69.00 \\
38.7 & 73.40 \\
41.2 & 80.10 \\
\hline
\end{tabular}

The bolling points of all the hydrocarbons agree very well with the values given in the literature. The bolling points of Methyl cetylene obtained by Preparation I and Preparation II agree within $0.1^{\circ} \mathrm{C}$. The same result is found for Bthyl Acotylene.

This value for Methyl acetylene $\left(-23.3^{\circ} \mathrm{c}.\right)$ shows fair agreement with that $\left(-23.0^{\circ} \mathrm{C}\right.$ ) obtained by R.N.Meinert and C.D.Hurd ${ }^{20}$ but is considerably higher than that found by Maass and Wright ${ }^{7}$. The amoant of material available for parification by Masss and Wright was considerably less 
and the data given above for Methyl Acotylene may be belleved more accurate for this reason.

The boiling point found for Ethyl Acetylene $\left(8.6^{\circ} \mathrm{C}\right)$

agrees with the values in the Iiterature ${ }^{21}$ and likewise

for Propyl doetylene $22\left(39.7^{\circ} \mathrm{C}\right)$ and Dimethyl cotylene 23 $\left(27.1^{\circ} \mathrm{C}.\right)$. 
TABLE 4.

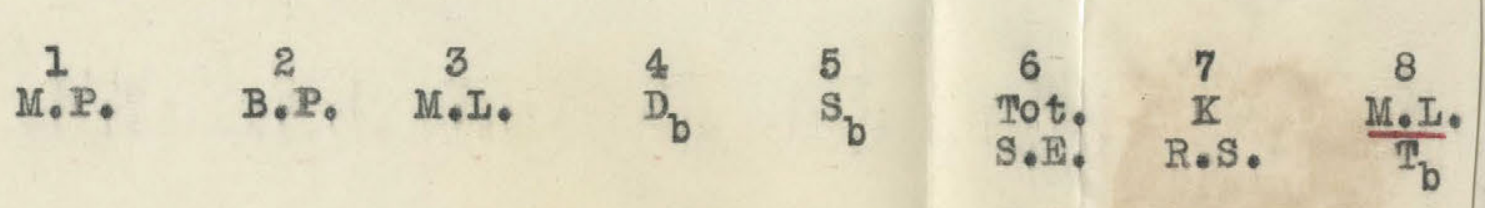

Compound

Fthone

Pthane

$-172.0$

$-88.3 \quad 3880$

Propane

$\mathbb{N}$-Butane

$-189.9$

$-44.5 \quad 4700$

. 5469

16.05

$45.7 \quad 1.98-21.0$

$50.3 \quad 2.15 \quad 20.6$

$47.8 \quad 2.21 \quad 20.5$

I-Butane

$-135.0$

$-0.5 \quad 5597$

$.6014 \quad 14.90$

$-145.0$

$-10.25480$

Ethylene

$-169.4$

$-103.9 \quad 3510$

$.5944 \quad 14.10$

Propylene -185.2

$-47.0 \quad 4600$

$\alpha$ Butylene $\quad-190.0$

- 6.15400

B Butyleno -127

1.0540

$\gamma$ Butylene -146.8

$-6.6 \quad 5200$

$-83.6 \quad 4273$

Acetyleno - 81

Methyl " -101.5

$-23.3 \quad 5562$

$8.6 \quad 5983$

Ethyl

$-122.5$

Dimethyl

Acetylene - 24.0

Propyl

Acetylene -98.0 $\begin{array}{llll}27.1 & 6434 & .6873 & 17.40\end{array}$

$\begin{array}{llll}39.7 \quad 7087 & .6718 \quad 17.00\end{array}$ $\begin{array}{cccccc}9 & 10 & 11 & 12 & 13 & 14 \\ T_{c} & T_{b} & \nabla_{m} & \text { Par. } & \text { Par。 } & \% \\ \text { Calc. } & T_{0} & & \text { Obs。 } & \text { Calo. Diff. }\end{array}$

$\begin{array}{llllll}34.6 & .60 & 54.9 & 110.4 & 112.2 & 1.6\end{array}$

$\begin{array}{llllll}91.6 & .62 & 75.0 & 150.6 & 151.2 & 0.4\end{array}$

$\begin{array}{llllll}147.0 & .64 & 96.3 & 190.6 & 190.2 & 0.2\end{array}$

$\begin{array}{llllll}129.5 & .64 & 97.6 & 188.8 & 190.2 & 0.2\end{array}$

$\begin{array}{llllll}5.9 & .60 & 49.1 & 99.4 & 101.2 & 1.8\end{array}$

$\begin{array}{llllll}91.3 & .62 & 69.0 & 139.7 & 140.2 & 0.4\end{array}$

$\begin{array}{llllll}145.0 & .64 & 89.5 & 179.9 & 179.2 & 0.4\end{array}$

$\begin{array}{llllll}156.0 & .64 & 88.9 & 178.7 & 179.2 & 0.3\end{array}$

$\begin{array}{llllll}147.0 & .64 & 89.3 & 178.4 & 179.2 & 0.4\end{array}$

$\begin{array}{llllll}39.7 & .61 & 41.9 & 88.1 & 90.4 & 2.6\end{array}$

$\begin{array}{llllll}121.6 & .62 & 59.7 & 12 \% .5 & 129.4 & 1.5\end{array}$

$\begin{array}{llllll}190.5 & .61 & 80.8 & 167.2 & 168.6 & 0.8\end{array}$

$\begin{array}{llllll}215.5 & .61 & 78.6 & 160.7 & 168.6 & 4.6\end{array}$

$220.3 \quad .63 \quad 101.3 \quad 206.2 \quad 207.2 \quad 0.5$ 
Discussion.

The constants determined for all the hydrocarbons investigated so far in this laboratory are compiled in Table 44. The two and threo oarbon oompounds were investigated by Wright ${ }^{7}$ and the three butylenes and two butanes by coffin ${ }^{10}$. In the disoussion of this table homologous and is omeric relationships will be considered separately as far as possible in order to aroid confusion. The properties considered will, ingeneral, be taken up in the order in which they appear in the tablo.

The pizsical properties of the first fow members of an homologous series are of perticular interest in that the majority of the properties of these compounds show distinot anomalies which oannot be fitted in with the higher members of the serles. These peouliarities ususily vanish and the series "constants" become constant with the four or five carbon compounds. It is an interesting possib1lity that the study of the lower and more simple members of a series may throw oonsiderable light on the properties and struoture of carbon chains by bringing out various faotors that are masked in the higher members by the larger weight of the molecule and the greater length of the ohain.

In considering the homologous relationships brought out in the abore table it is seen that the well known rule of alternating melting points (oolumn 1) is obejed in the paraffin series, the compounds ethane and butane, with an even number of oarbon atoms esoh having a higher melting 
point than propane with three oarbon atoms. This somewhat dubious rule does not hold for the unsaturated olefine and acetylene series and indeed the extremely low melting point of $x$ butylene is a surprising exception to the genersl rule, obeyed in every other oase in the above table, that the melting point of an unsaturated stralght chain oompound is higher than that of the saturated compound with the same number of oarbon atoms. This is seen to be the oase for the acetylenes whose melting points are,for compounds containing the same number of oarbon atoms, above either the paraffins or olefines.

The variation of melting point due to structural differences in the moleoule is strikingly demonstrated in the butylenes and the is omerio acetylenes, dimethyl-ace tylene and ethyl-acetylene - all containing four carbon atoms. In oonsidering these compounds it is seen that insaturation in the acetylenes apparently accounts for their higher melting points. Further more symmetry of the moleoule seoms to play an important role in governing the melting point. The unsymmetrical butylenes have the loweat while $\beta$ butylene has the highest melting point of the butylenes. This is also seen to be the case with ethyl-acetylene and dimethylacetylene.

The reason why the introduction of a double or triple bond should raise the melting point of a substance is to be looked for in the increased stray field due to unsaturation which thus increases the attraction between the molooulos. 
The properties observed at higher temperatures such as bolling points, moleoular latent heats of evaporation and oritical temperatures are, as would be expeoted, praotically uninfluenoed by this inoreased attraotion.

These more aditive properties boiling point (column 2) and molecular latent heat of evaporation (column 3). vary much more regularly than the markedly constitutive melting points. The critical temperatures (column 9) also conform to this same tendency. These properties in the acetylenes are seon to be consistently higher than for other compounds with the same number of carbon atoms and rise as would be expected with increase of molecular weight. The symmetrioal dimethyl-acetylene has a higher bolling point than 1ts; 1somer ethyl-ace tylene.

A consideration of the properties mentioned above loads to a very definite distinction, when compounds having the same number of carbon atoms are compared, between the members of the acotylene series on the one hand, and those of the parafin and olefine on the other. As stated, the bolling points, moleoular latent heats of evaporation $y$ and oritical temperatures are distinctly higher for all the acetyinenes then for their corresponding compounds in the other two series, although their molecular weights are actually less. Thus it is seen that ethane and propylene have bolling points $-88.3^{\circ} \mathrm{C}$, and $-103.9 \mathrm{C}$. respectively and that they are below acetylene whose bolling point 1s $-83: 60$. 
This tendeney is followed throughout by propane, propylene and methyl-acetyleno;butane, butylenes and ethyl-acetylene. on comparing the molecular latent hests of evaporation it is seen that the decrease of ethylene under ethane is approximately of the same order of magnitude as the decrease in molecular weight. For acetylene, whose molecular weight is still lower, there is a decided increase in this constant entirely inconsistent with the behaviour of the preffins and olefines. Iikewise this is seen to be the case for the three carbon compounds propane,propylene,allylene and also in the four carbon group, butane, butylenes, dimethyl-acetylene and ethyl-acetylene.

This same apparent anomaly is paralleled in the values for the critioal temperatures. In the two carbon compounds acetylene, with the lowest molecular weikht, has the highest value for this constant. Similarly in the three and four carbon groups.

Hence, after a comprehensive survey of this data, it is possible to classify the parafins and olefines together but the acetylenes show a distinct difference from the other two series. This is connected with what will be brought out later on, namely, that the acetylene linkage is af a more definitely pronounced polar character than is the oase in the parafin and olefine series.

The boiling points on the "corresponding" temperature scale (column 10t agree very well among themselves and bring out very well the simple and ideal nature of these liquids. 
The Ramsay and Shlelds constants (column 7 ) also furnish evidence for the unassociated normal condition of all these substances in the liquid state although the values obtained for the Ramsay and Shields constant in the acetylenes seem to be consistently lower.

The abnormality of the first two members of each series 1s well brought out by the rapid initial inorease of the densities at the boiling point (column 4). The total surface energy (column 6 ) is seen to increase for the first two members of all series.

This quantity, total surface energy, is of particular value in that it solves the question of the temperature at which the surface tensions of different liquids should be compared. The fact that $\frac{d s}{d t}$ is Iinear makes $U$ constant in the following equation in whioh $U$ is the total surface energy and $S$ is the surface tensiton at the temperature $T$.

$$
U=S+T \frac{d}{d T}
$$

Sinee $\frac{d S}{d T}$ is strictiy linear only at a considerable distance from the oritical temperature $U$ will not be oonstant if oaloulated from surface tensions measured at too high a temperature. This total surface energy which is thus a constant for any partloular liquid is of ospooial importance in homologous series when considered in the light of modern surface phenomena. The widely accepted views of Langmuir ${ }^{1}$ 
and Harkins ${ }^{2}$ in this respeot may be summed up as follows. The molecules at the surface of a liquid are under a differential force due to the moleoules beneath them and thus tend to be drawn by this attraction into the body of the liquid. Sinoe this force acts only over a very short distance a long molecule with a polar group at one end e.g. one of the higher fatty aolds will tend to orient Itself in a direction such that it s potential energy is a minimum. In other words the polar group being at the end of the molecule most strongly attracted will penetrate into the liquid leaving the carbon chain normal to the surface. Since the surface energy of a liquid is mainly due to groups possessing stray fields of force, $1 . \theta$. polar groups, it follows that the farther the polar group penetrates beneath the surface the smaller will be the surface energy. The longer a molecule the farther will its:" polar group be from the surface so that in ascending an homologous series of such compounds the surface energy should tend to become constant when the surface consists entirely of $\mathrm{CH}_{3} \mathrm{CH}_{2}$ groups. Moreover all homologous series having a $\mathrm{CH}_{3} \mathrm{CH}_{2}$ at one end of the chain should approach the same limiting value.

This constant for the higher paraffins has been found to 1 ie between 46 and 48 , values which theoretically should include the surface energies of all members of the series. This is seen to be the oase for ethane and the two butanes. 
The high value for propane is a distinct anomaly for which at presint there seems to be no explanation. (column 6 ). The change from parafins to the corresponding olefines produces, es would be expected, a small 1ncrease in total surface energy. On going from the olefines to the acetylene series the increase is much more marked but seems to become less distinot when the butylenes are compared with the four oarbon acetylenes ethyl-acetylene and dimethyl-acetylene. When considering the property total surface energy in relation to the first few members of an homologous series two classes of compounds may be seperstely classified. There are first those in which there is no polar group attached to the molecule such as the paraffins and olefines listed above. Secondly there is a lirge number of compounds, such as the alcohols and fat acids, which possess a highly polar group attached to one end of the molecule.

As can be seen from the data assembled in Table 4 the total surfaco energies of those compounds belonging to the first class increase slightly until a more or less limiting value is reached. In the olefine series, where this increase is most marked, the change from ethylene to propylene is greater than from propylene to normal butyleno. That this difference should seem smaller with inoreased length of chain is explained by modern theory as being the 
result of the greater orientation in the osse of the longer molecule 1.e. those having the greater moment.

In compounds of the sec ond type, that is those possessing a polar group on the end of the carbon chain, an entirely different result is observed. Several homologous series of this kind have been investigated such as the aloohols and fatty acids. Hunten and Mass ${ }^{24}$ studied the variation of total surface energy for the fatty aolds and obtained the following results:

\begin{tabular}{lc}
\multicolumn{1}{c}{ Acid } & Total Surface Energy \\
Formic & 63.6 \\
Acotic & 58.2 \\
Propionic & 56.9 \\
Butyric & 54.4 \\
Iauric & 54.6 \\
Palmitic & 54.5 \\
Stearic & 54.8
\end{tabular}

From these data it is seon that for this class of compound the total surface energy falls off very rapidy as the eeries is asconded and reaches a normal value for all the higher members of the series. This same result has been found in other homologous series whose members contain a polar group. When the total surface energies of the acotylenes are compared it is seen at noe that they follow this 
general tendency i.e. to decrease to a normal value with increase of carbon chain. This evidence points to the fact not encountered in the paraffin and olefine series, that the acetylene linkage, a triple bond, exerts a decidedly polar influence on the molecule.

It was pointed out in the general introduction that the more symmetrioal a molecule is, the greater is it's attraction for moleoules of the same species, and consequently the smaller is it's attraction for molecules of a different species. Thus it would be expected that dimethyl-acetylene, being the symmetrical isomer to ethyl-acetylene, would have a higher surface tension at the bolling point as is exemplifled in the case of the butglenes where the symmetrical (3 butylene has the highest value for this constant, (column 5). This theory is apparently not supported by the data obtained for the acetylenes since it is seen that the value for this constant is less for the symmetrioal dimethyl-acetylene than for 1t's ungymmetrical is omer ethyl-acetylene.

It must be remembered, however, that in this particular case the symmetry of the molecule is around a polar group whose polarity is of another order of magnitude than that of the olefine serles. Since the property of surface tension is partioularly sensitive to this faotor it may well be due to this that the symmetrical dimethyl-acetylene 
has smaller surface tension at the boiling point. As will be pointed out more fully later on the polarity and consequently the attractive forces due to the polar group may possibly be partly noutralized in this case by the very fact that the molecule is symetrioal.

The molecule of dimethyl-acetylene may be represented 8. :

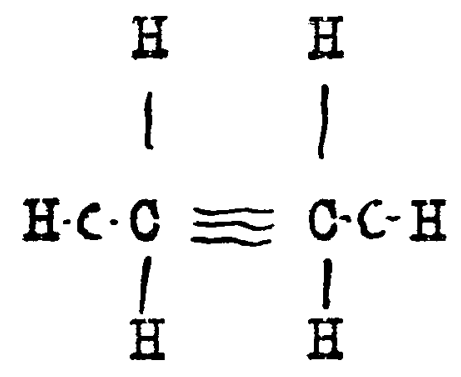

Represented in this way it is seen that the hydrogen atoms overlap and obscure the effect of the highly unsaturated triple bond and,as many of it's properties seem to indicate, cause the compound to behave as if it were partially saturated as far as the pronounced unsaturation of an acetylene linkage is conoerned.

In consequence of this, in adition to the polarity effeot, it would be expeoted that the surface tension at the bolling point would be smaller, since the molecular foroes of attraction would be considerably lessened by the shielding effect of the hydrogen atoms and the strain caused by such a distortion. This is seen to be followed out in all the properties depending on surface tension. A comparison of the surface tensions at the bolling point of dimethyle acetylene and 1t's 1somer ethyl-acetylene shows, as would be expeoted from this point of view, a lower value for dimethyl-ace tylene. 
The moleoular volume at the bolling point has long been reoognised as probably the most additive property of chemical compounds and one which should lend itself readily to calculation and prediotion. Amongthe various relationships conneoting molecular volume and structure, that of $K_{0 p p^{25}}$ is probably the most satisfactory and has been most widely used. Although Kopp's apparent insistanoe on the striotly aditive nature of volume has been discred. Ited for a considerable time it is only very reoently that any satisfactory substitute for his constants, or any reliable rules connecting volume and constitution were suggested. It was pointed out by Moleod 26 that the following relation between surface tension and density appeared to hold over a wide range of temperature and for very different chemical substances, In this equation :

$$
s=c(D-a)^{4}
$$

$S$ is the surface tension, $D$ and $d$ are the liquid and gas densities all at the seme temperature. $C$ is thus a oharacteristic constant independent of temperature for normal unassociated liquids. By rearranging the above eavation and multiplying by $M$, the molecular welght, Sugden ${ }^{27}$ showed that for different liquids $P$ in the relation:

$$
\mathbf{P}=-\frac{\mathrm{M}}{\mathrm{D}-\mathrm{d}}-\mathrm{s}^{\frac{1}{2}}
$$

represents the molecular volume for temperatures at which 
the liquids have the same surface tension. Thus for different Ilquids this quantity which Sugden terms the "parachor" can be considered as the molecular volume measured at the same internal pressure. The quantity $\bar{D}=-\bar{d}$ has the dimensions of volume and at low temperatures, where a becomes negligible, is really the molecular volume. From the study of a large number of liquids Sugden has determined the ralues of several atomic and structural parachors which are found to be remarkably aditive. He assigns carbon the value 4.8, hydrogen 17.1, the double bond 23.2 and the triple bond 46.4 .

In oolumn 12 of Table 4 are listed the values of the parachors caloulated from the density and surface tension data of these compounds. The next column gives the parachor oalculated from Sugden's values. Column 14 shows the per centage differences between the observed and calculated values. In most cases the agreement is very good but irregvlarities are noticed in the two oarbon compounds and for dimethyl-ace tylene.

That Sugden's values for the parachor can not always be relied on in special oases dealing with compounds that differ widely in constitution has been pointed out by Mumford and Phillips ${ }^{28}$ in connection with investigations they have made on a considerable number of compounds. 
It has beon stated above that dimethyl-acetyleno appears to exhibit pronounced properties indicating that it's molecule is decidedly polar. In addition to this there is also evidefoe for the assumption that the molecule behaves as if the attractive firces, due to the triple bond, were masked, apparently by the symmetry of the molecule, so that it resembles a more saturated molecule in certain properties. Thus it is not surprising to find that the parachor, which is directly related to surface tension, should have a value lower than the theoretical based on Sugden"s values, whioh do not take into aocount "strain faotors".

Since the parachor is virtualig a measure of molecular volume under comparable conditions in regard to internal pressure, and 1s, therefore, more or less independent of the cohesion between the molecules, the contractions referred to as strain constants would appear to cause a real diminution in molecular volume brought about elther by the oloser packing of atoms and groups within the molecule or by a decrease in the effective size of one or other of the atoms concerned. That a strain constant exists in the case of dimethyl-acetylene may be indicated by the fact that it's molecular volume is lower than ethyl-acetylene. In consequence of this strain discrepensies in the value obtained for the parachor are not to be unexpected. 
Iet us consider the acetylenes and dimethyl-8ce tylene in particular, from another point of view and confine the discussion to an empirical oonoeption of the behaviour of th1s group of compounds.

It has been shown that the molecular volume at the bolling point,from a theoretical point of view, should give a comparative value of the actual volume of moleoules. This rolume has been foind to be an additive-constitutive property or, inother words, additive from the point of view of definite values agsigned to the atoms of elements that are linked up In a definite way. Thus carbon and hydrogen in all organio compounds may be assigned definite values where the carbon has four ordinary linkages. Unsaturation requires the addition of a constant value depending on whother th unsaturation is of an ethylene or acetylene linkage. The latter has the larger value and the greater the extent of unsaturation the greater is the rolume of the compound above that given by the straight aditive ralues of the atoms of the elements involved. Using Kopp"s values for the molecular volumes of carbon and hydrogen at the bolling point, where $0=2 H=11$, the moledular volumes of the acetylenes derived by these constants are given in the following table and compared with their experimental values determined from the density at the bolling point. 


$\begin{array}{lccc} & \text { Kopp's } & \text { Exp'mtI } & \text { Diff. } \\ \text { Acetylene } & 33.0 & 41.9 & 8.9 \\ \text { Methyl Acetylene } & 55.0 & 59.7 & 4.7 \\ \text { Ethyl Acetylene } & 77.0 & 80.8 & 3.8 \\ \text { Dimethyl Acetylene } & 77.0 & 78.6 & 1.6 \\ \text { Propyl Acetylene } & 99.0 & 101.3 & 2.3\end{array}$

It is at once seen that the difference in volume caused by the triple bond is greatest for acetylene and falls off rapidiy as the series is asconded. What is not so easily understood is the fact that the difference between these values in the oase of the isomers is much less for dimethylacetylene than it is for othyl-acetylene.

However the interpretationmade possible by this apparent anomaly goes further to substantiate the theory that the molecule of dimethyl-acetylene is rendered less unsaturated by the symmetry of it's structure. Due to this symmetry the increase of volume over the empirical value, assigned by Kopp's the for the triple bond, 1s lossened by more than half so that, instead of the increase expected by the introduction of a triple bond, there is found a value that would suggest that the compound was considerably less unsaturated.

This evidenoe, obtained from an entirely empirical point of view, falls in agreoment with and moreover substantiates the same conclusions draw from a consideration of the caloulated values obtained from surface tension measurements. 
The correlation of the data from these two points of view lends further strength to the theory that in dimethylscetylene the unsaturation of the triple bond is considerm ably obscured by the symmetry of the molecule.

Dimethyl-acetylene can be prepared by the sction of heat on a mixture of ethyl-acetylene and alooholic potash. This would tend to indicate that the potential energy of the dimethyl-aootylene moleoule 1s, if not aotually at a minimum, considerably less than that of ethyl-acotylene. This is further supported by the lower values obtained for surfaco tension and totel surface energy.

Among other chemical properties the relative esse of bromination of the butylenes and acetylenes may be compared. Coffin, 10 on work done in this laboratory in connection with the bromination of the butylenes, found that the dibrombutanes could be prepared readily from these compounds. In contrast to this the complete saturation of the molecule of dimethyl-acetylene was accomplished, as described above, with considerable difficulty and under the catalytic influence of ultra violet light. This result is not to be unexpected sinoe, apart from the conoept of it's lower potential energy, the ohemical reactivity of dimethyl-acetylene is probably quite inhibited by the symmetry of it's molooule.

Finally it may be said that all the propertios of dimethyl-acetylene pelation to members of it's own homologous series and to members of the parafin and olefine series, whether physioal or chemical, point to the fact that it's 
behaviour is greatly influenoed and inderd controlled by it's polarity and moleoular strain. The latter is caused possibly by the shielding effect of the hydrogen atoms which is so noticeable on aocount of the symmetry of the molecule.

In this respect it would be most interesting, although the time alloted to the work desoribed in this thesis does not permit, to compere the relative rates of reaction velooity for the acotylenes along lines similar and analogous to those followed by former investigators in connection with the reaction velocities of the butylenes and hydrogen chloride. This work is described in an earlier part of this thesis. The results of such an investigation would, it is belleved, further substantiate the data already obtained for the acetylenes. It would be expected that an inrestigation of this sort would show that dimethyl-acetylene, in relation to the other members of 1t's series and in particular to it's isomer ethyl-acetylene, would have a much slower rate of velocity of chemical reaction and behave in this respeot muoh as the symmetrical $\beta$ butylene of the olefine series. This is an avenue for future work which lack of time prevents in this investigation but on that would jield highly interesting and informative results.

In conclusion it may be said that, as a class of compounds, the acotylenes stand out separately and distinctly from the parafing and olefines as far as the physioal 
propertios and their interpretation is concerned. This is manifested in several instances by the comparison of their physical properties with those of the other two series. Decrease in molecular weight in the parafin and olefine series causes, as would be expected, for compounds of the same number of carbon atoms, a lowering of such constants as boiling point,oritical temperature etc. These constants are seon to rise for the acetylenes in spite of their lower molecular weight. The total surface energies of the acotylenes follow a tendency differing from that of the parafins and olefines showing that they exhibit polar characteristios not shared by the other series.

That the acetylene linkage imparts to the oompounds comprising this homologous serles a polar tendeney is made strikingly evident by the properties of dimethyl-acotylene, The properties of it's isomer, ethyl-soetylene, exhibit, parallel to the other members of $1 t^{\prime}$ s series, this observed polarity but the faot that in dimethyl-goetylone the polarity Is considerably masked by the symmetry of the molecule brings to the fore with even more emphasis the polar properties of the acetylenes as a whole.

Due to the saturation of the paraffin series 1 t would not be expected that they would exhibit polarity in any of their properties. On passing from this series to that of the olefines it might be thought that some degree of polarity would be involved in consequenoe of thetr unsaturation. 
That no property of this sort is present may be observed by a consideration of their physioal oonstants. No divergenoes in the properties of $\beta$ butylene, the symmetrioal olefine corresponding to dimethyl-acetylene, are noticed which would probably be the case if pronounced polarity in this series existed. As unsaturation is increased resulting in the acetylene series an entirely different aspect is presented. All the properties that would be influenced by polarity of the molecule are seen to manifest this characteristic by their divergence from the general tendenoles observed in the paraffin and olefine series. This makes it apparent that the acetylene series possesses a property that sets it apart as a separate class of compounds from the paraffins and olefines namely that the molecules of the members of this series exhibit a definite polar tendency. 


\section{Summary -}

The aliphatio scetylenes, methyl-, ethyl-, and propylacetylene have been prepared by the method of Iebeau and Picon. A description of this mothod, whioh consists in the alkylation of sodium acetylide in liquid ammonla, is given. Its value as a means of preparing the hydrocarbons in a state of puritiz is emphasized. Method has been evolved for the preparation of dimethyl-acetylene along lines analogous to those used in preparing the simpler aliphatic acetylenes. For this preparation the sodium-methyl-acetylide was methylated in a reaction medium of licuid ammonia.

These hydrocarbons were prepared and very carefully purfifid for the purpose of determining their physical constents. The date obtained are melting points, boiling points, density and surface tension measurements over a temperature range suitable for each hydrocarbon and other constants calculated from the values so sbtained such as molecular latent heat of vaporisation, critical temperature and parachor etc.

These physical constants have been accurately determined in order to compare the hydrocarbons from the point of Tiew of molecular forces of attraction. The interpretation of these data makes possible a comparison of these acetylenes not only among themselves but with special reference to the parafin and olofine series. The fact that othyl-aoetylene and dimethyl-acetylene are isomers,each possessing lour carbon atoms, and, moreover, can be compared with the butylenes 
lends an added significance to the theoretical aspect of the work.

- It is found, when the physical data for paraffins and olefines are compred, thet the acetylene series exhibits pronounced polar tendencies that distinguish it from the other two series. The reality of this distinction is apperent from considerations of various properties with special reference to the total surface energy.

The properties of ethyl-acetylene are compared with those of its symmetrical isomer dimethyl-acetylene. The most striking difference is observed in the values obtained for the parachor and molecular volume. Both these constants are seon to be considerably lower for dimethyl-acetylene. The interpretation put upon these differences leads to the conclusion that dimethyl-acetylene, due to the shielding effect of its symmetrioally arranged hydrogen atoms, behaves as if it were considerably more saturated than its fellow members of the ectylene series.

The existence of a greater saturation in the symmetrical dimethyl-acetylene is further dmonstrated by the fact that its polarity is considerably lessened so that in this respect it resembles the members of the olefine series.

In spite of the fact thet the acetylenes have lower molecular weights those constants usually dependent on such a property as melting point,boiling point,critical temperature etc. are shown to be consistently higher than for the members 
of the paraffin and olefine series. This, together withthe concept of their polarity, leads to the conclusion that of the three series the acetylenes are to be classified separately as far as their physioal properties are concornod. 
The author's olaims to originality and contribution to knowledge are :

1. Certain modifioations in the Iebeau Pivon method for the preperation of aliphatio aoetylenes and the faot that ethylm, and methyl-acetylene oan be dried by passing the gases over phosphorous pentoxide without the possibility of their polymerization.

2. (a) The determination of the physioal properties of methyl-, othyl-, propyl- and dimethyl-seetylene by physical chemical mothods.

(b) Where methyl-acetylene had been investigared before this work includes a refinement and correction of the values previously obtained.

(c) Melting points of these hydrocarbons have been socurately determined for the first time.

(d) Vapor pressures of the hydrocarbons were determined for the first time over a temperature range resulting, by this physical chemioal method, in a more accurate messurement of all the bolling points.

(e) Messurements of the density and surface tension were made for those hydrocarbons over a temperature range. These data, together with the constants caloulated from them, have been determined for the first time. 
(f) Dimethyl-acetylene has been prepared for the first time by methylating the sodium-methyl-aoetylide in Ilquid ammonia although this mothod has boen indicated before.

(8) Dimethyl-acetylene shows in its properties distinct anomalies. The parachor is considerably lower than that of 1ts 1somer ethyl-acetylene. This is interpreted to mean that dimethyl-acetylone behaves as a more saturated compound than the acotylene linkage would imply. The posvibility of a strain constant to be appliod in the osloulations for the parachor is suggested.

(h) The aostylene serieg 1s distinguishod fron the peraffin and olofine serios in that it possesses pronouncod polar tenden cies. 
BIBIIOGRAPHY.

1. Langmuir.

"Met. Chem. Eng." 15:468:1916

J. A. C. S. 39 : $1848: 191 \%$.

2. Harkins.

$$
\text { J.A.C.S. } 39: 354,541: 1917
$$

3. Taylor;H.S.

Treat1se on Physical Chemistry. P. 107.

4. Maass, O, and Morrison,D.M.

$$
\text { J.A.C.S. 45:1675-1682:1923. }
$$

5. Maass, 0 , and Russe11, J.

$$
\begin{aligned}
& \text { J.A.C.S. } 40: 1561-1573: 1918 \\
& \text { J.A.C.S. }
\end{aligned}
$$

6. Maass, O.,Boomer, E.N. and Morrison, D.N.

$$
\text { J.A.C.S. 45:1433-1438:1923. }
$$

7. \& 8. Maass, $\mathrm{O}$, and Wright, $\mathrm{C} . \mathrm{H}$.

$$
\begin{aligned}
& \text { J.A.C.S. } 43: 1098-1111: 1921 \text {. } \\
& \text { J.A.C.S. } 46: 2664-73: 1924 \text {. }
\end{aligned}
$$

9. Maass, 0, and Siveritz,C. J.F.C.S. 47:2883-91:1925.

Ph.D. Thesis MoGill Unieersity. 
10. Maass, 0. \& Coffin, C.C.

Trans. Roy. Soc. Can. III 21:33-40:192\%.

Can. Journ. Res. 3:526-39:1930.

J.A.C.S. 50:1427-37:1928.

$\mathrm{Ph} . \mathrm{D}$. Thesis MoGill University.

11. Iobeau \& Picon.

c. r. 156:1077.

C. f. $158: 1184,1346$.

12. Ploon.

$$
\text { C. r. } 168: 895,825 \text {. }
$$

13.

Faworsky •

$$
\begin{aligned}
& \text { J.Pr. (2) } 42: 143: 1890 \text {. } \\
& \text { J. } \operatorname{Pr} \text { (2) 37:385:1888. }
\end{aligned}
$$

14. Iebeau.

$$
\text { c. r. 157:137-39. }
$$

15. Hiebermann

$$
\text { A. } 135: 268 \text {. }
$$

Kutscherav.

B. $17: 25$.

16. Annalon of Russian Journal of Physical Chemistry. 13:392

17. Faworsky.

$$
\text { J. Pr. (2) 42:144. }
$$


18.

Boilstoin P. 122.

19.

Riohards.

J.A.C.S. 37:1656:1915.

20.

Me inert, R.N. \& Hurd,C.D.

$$
\text { J.A.C.S. 52:4540-49:1930. }
$$

21. Ploon.

$$
\text { c.r. 158:1184. }
$$

22.

Iobeau \& P1oon.

$$
\text { c.r. } 158: 1346 \text {. }
$$

23.

Faworsky

$$
\text { J.Pr. (2) 42:144. }
$$

24.

Hunton \& Masss

$$
\text { J.A.C.S. 51:153:1929. }
$$

25.

Kopp.

$$
\text { Annalen 96:153,303:1855. }
$$

26.

McLo od.

Trans. Farady Soc. 19:38:1923.

27.

Sugden.

$$
\begin{array}{lr}
\text { J.C.S. } & 125: 1177: 1924 . \\
\text { J.C.S. } & 127: 1868: 1925 \\
\text { J.C.S. } & 1055: 1929 .
\end{array}
$$

28. Mumford \& Phillips.

$$
\text { J.C.S. } 1929: 2112-33 \text {. }
$$






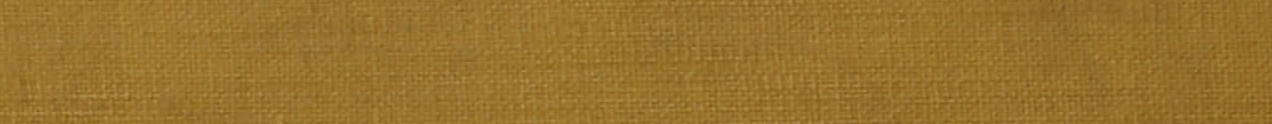

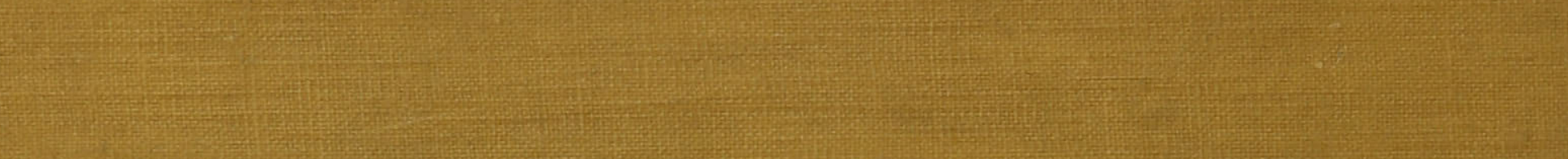

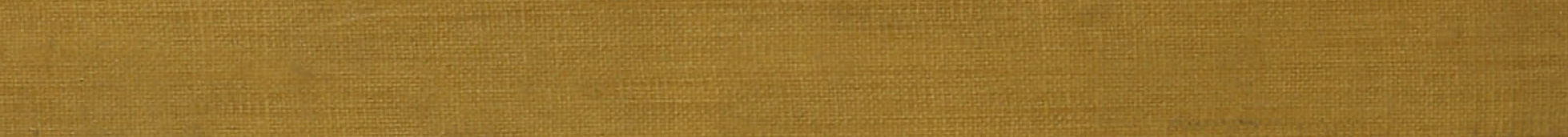

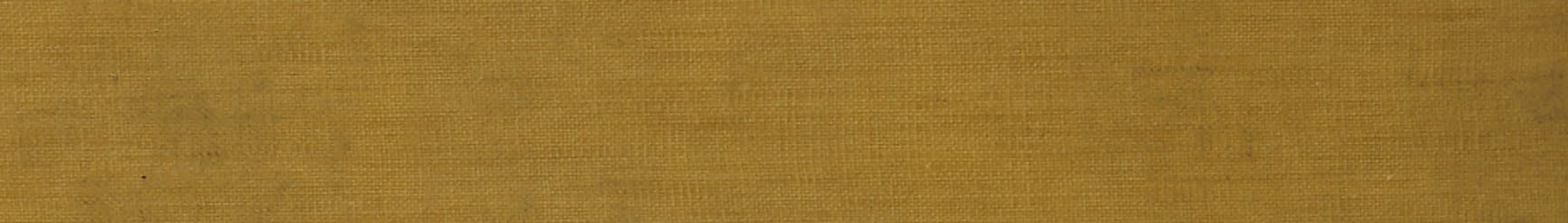

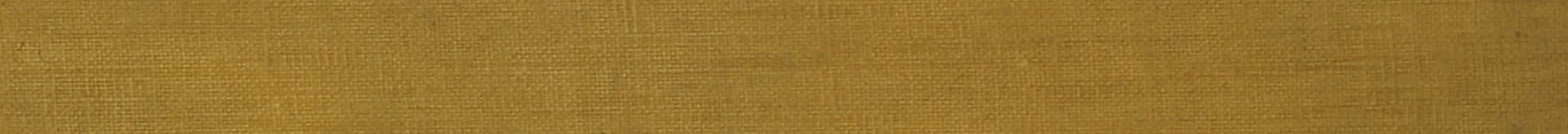

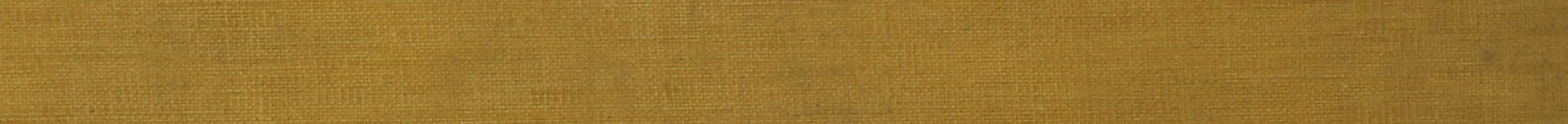

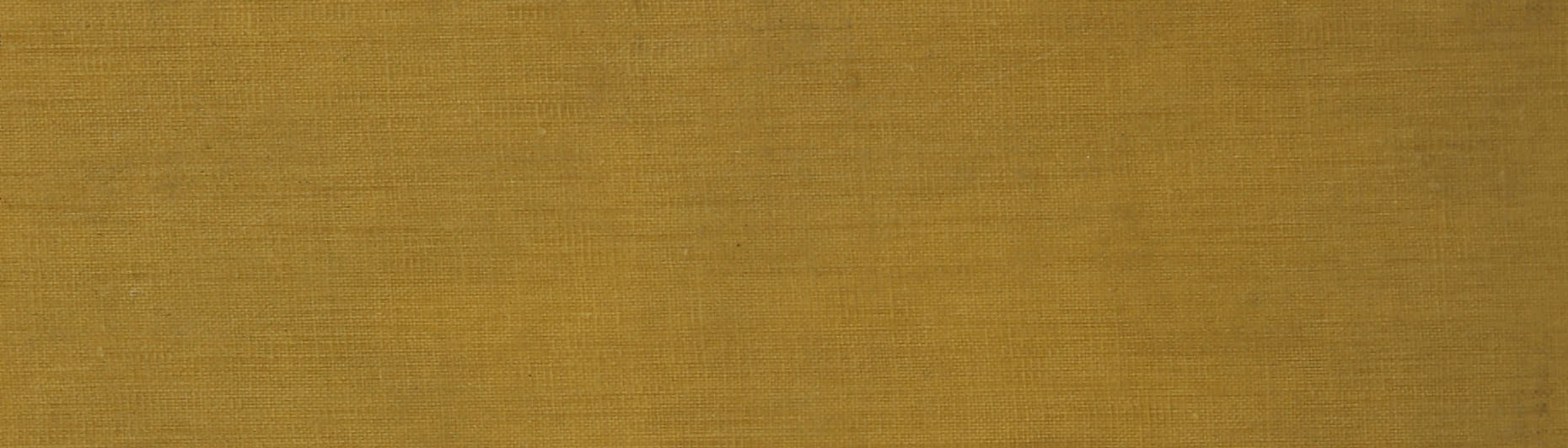
(1)

$\sin (x)$

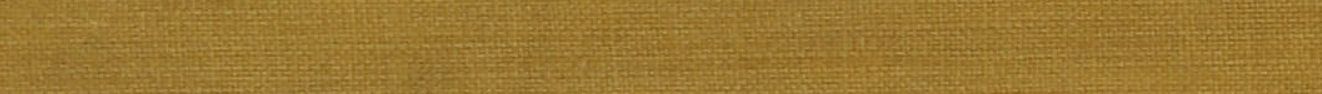

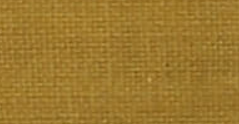
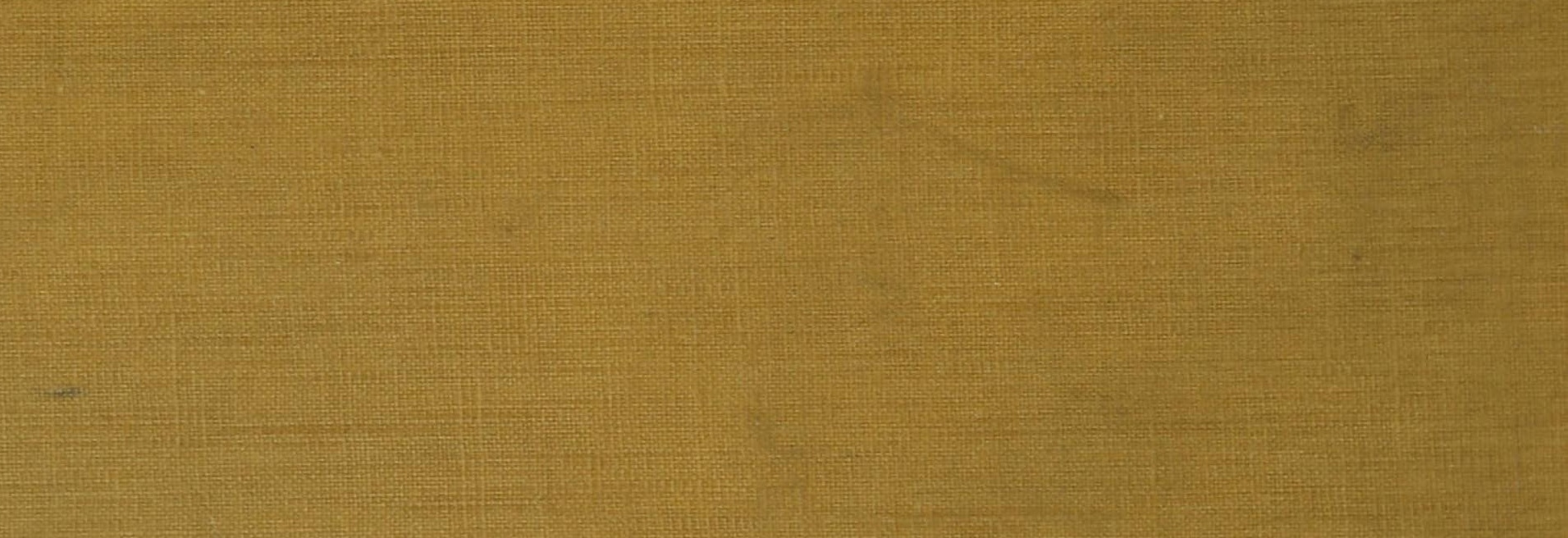

$\sin 20$

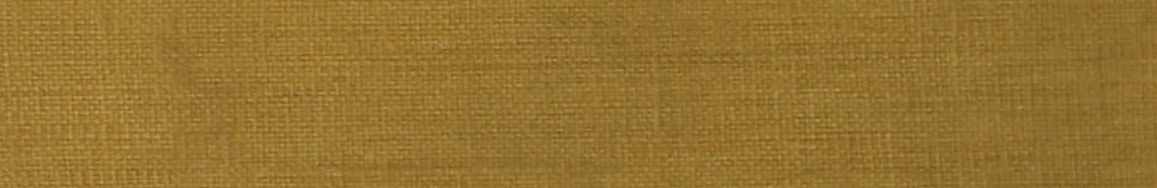

The

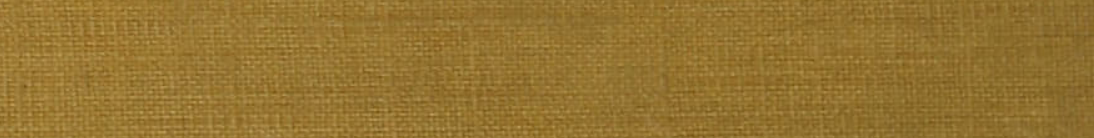

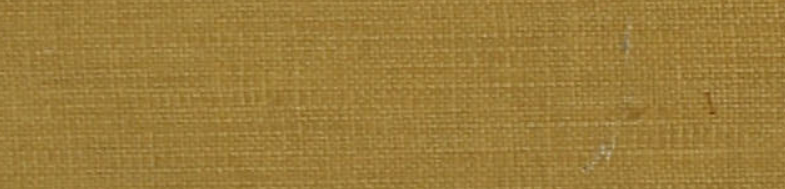

